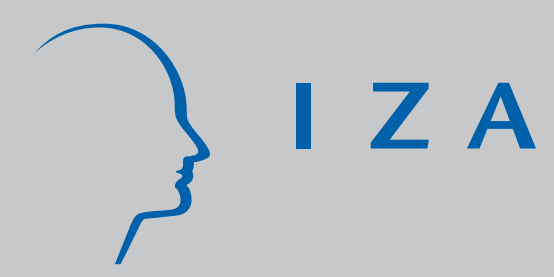

IZA DP No. 1273

Carefree? Participation and Pay Differentials for Informal Carers in Britain

Axel Heitmueller

Kirsty Inglis

August 2004 


\title{
Carefree? Participation and Pay Differentials for Informal Carers in Britain
}

\author{
Axel Heitmueller \\ Department for Work and Pensions, London, \\ London Business School and IZA Bonn \\ Kirsty Inglis \\ Department for Work and Pensions, London
}

Discussion Paper No. 1273
August 2004

IZA

P.O. Box 7240

53072 Bonn

Germany

Phone: +49-228-3894-0

Fax: +49-228-3894-180

Email: iza@iza.org

Any opinions expressed here are those of the author(s) and not those of the institute. Research disseminated by IZA may include views on policy, but the institute itself takes no institutional policy positions.

The Institute for the Study of Labor (IZA) in Bonn is a local and virtual international research center and a place of communication between science, politics and business. IZA is an independent nonprofit company supported by Deutsche Post World Net. The center is associated with the University of Bonn and offers a stimulating research environment through its research networks, research support, and visitors and doctoral programs. IZA engages in (i) original and internationally competitive research in all fields of labor economics, (ii) development of policy concepts, and (iii) dissemination of research results and concepts to the interested public.

IZA Discussion Papers often represent preliminary work and are circulated to encourage discussion. Citation of such a paper should account for its provisional character. A revised version may be available directly from the author. 
IZA Discussion Paper No. 1273

August 2004

\title{
ABSTRACT
}

\section{Carefree? Participation and Pay Differentials for Informal Carers in Britain*}

\begin{abstract}
A substantial proportion of working age individuals in Britain are looking after sick, disabled, and elderly people and combine work and caring responsibilities. Using the British Household Panel Study (BHPS) for the years 1991 to 2002 this paper studies the determinants of labour market participation as well as earnings differentials for informal carers and non-carers over time. In particular, the paper decomposes participation and wage differentials for non-carers and carers and shows that carers are systematically disadvantaged. Furthermore, opportunity costs from forgone wages and wage discrimination are estimated and found to be substantial.
\end{abstract}

JEL Classification: J70, J31, J40, C23

Keywords: decomposition, fixed effects model, Markov transition, opportunity costs

Corresponding author:

Axel Heimueller

Department for Work and Pensions

Analytical Services Team

1-11 John Adam Street

London, WC2N 6HT

England

Email: Axel.Heitmueller@dwp.gsi.gov.uk

\footnotetext{
* We are grateful for comments by Richard Berthoud and William Collier as well as colleagues at DWP. The views expressed in this paper do not necessarily reflect the opinion of the Department for Work and Pensions.
} 
Introduction

According to the 2001 Census there were about 5.2 million informal carers in England and Wales - one in ten of the population - looking after sick, disabled, and elderly people. The General Household Survey estimates the total number to be 6.8 million carers for the whole of GB in 2000 (ONS, 2002). As will be shown in this paper more than $14 \%$ of the working age population is currently providing unpaid care. Many of them not only care for partners and family but also for friends and neighbours. Individuals who combine work and caring responsibilities often do so at the expense of career prospects, leisure time, income, and pension entitlements.

In the presence of an aging population and increasing longevity, informal care has become a vital part of the social network in Britain. Traditionally, the main policy tool to support informal carers has been Carers Allowance (CA $)^{1}$. A person qualifies for CA if they are caring for a severely disabled individual for more than 35 hours a week and are not in 'gainful employment' or fulltime education and are aged 16 and over. ${ }^{2}$ In 2002/03 the Government spent over $£ 15$ billion on residential and non-residential care (Laing and Buisson, 2003) and an additional £995 million on CA. The potential replacement cost to the State for informal care has been estimated to be approximately $£ 22$ billion in 1999 (Laing and Buisson, 2000) and it has been argued that given the substantial scale of the informal care market, even small changes in the willingness of people to provide care would significantly increase the demand for formal care (Laing and Buisson 2003).

Yet, these studies are based on a market valuation rather than an opportunity cost approach and, hence do not take into consideration additional costs such as lost income,

\footnotetext{
${ }^{1}$ Up to April 2003 Carers Allowance used to be labelled Invalid Carers Allowance.
} 
reduced career opportunities and deteriorating human capital. Opportunity costs are likely to be substantial as they are not only confined to the period of care but may impact on life events in the future. Clearly, any informed cost-benefit analysis will have to add opportunity costs to replacement costs of informal care such as CA expenditure. Hence, there is a conflict of interest from the policy maker's point of view. On the one hand, there seems to be evidence that informal care is less expensive and maybe even more effective than formal care leaving opportunity costs aside. ${ }^{3}$ Yet, from a carer's point of view unpaid caring reduces choice and opportunities.

The National Strategy for Carers (Department of Heath, 1999) recognises this dilemma to some extent and emphasis the importance of flexible working arrangements and the need to keep carers in touch with the labour market to ease re-employment once caring spells come to an end. Part of this commitment is currently met by the obligation of carers who are out of work and on CA to attend a Work Focused Interview (WFI).

The proportion of informal carers claiming CA is small compared to the overall number of unpaid carers. Only around 6\% of all carers are claiming CA. The group of carers not claiming CA has commonly been labelled hidden carers as these individuals are widely invisible to the Government because they are not claiming any benefit that identifies them as carers. This group is particularly suited to study the impact of unpaid care on labour market decisions and outcomes as they are not subject to, for example, earning limits as a consequence of CA rules.

Yet, despite its obvious labour market and health policy relevance and the sheer scale of the informal care market, informal carers have been neglected in the quantitative economics literature. An exception are the studies by Evandrou (1995), the Scottish

\footnotetext{
${ }^{2}$ For details on the CA rules see Child Poverty Action Group (2004). A person is defined to be severely disabled if they are entitled to higher or middle rates of Disability Living Allowance (DLA) care component, Attendance Allowance (AA) or Constant Attendance Allowance. Individuals are gainfully employed if they earn more than $£ 79$ per week after allowable deductions.
} 
Executive Central Research Unit (2001), and in particular Carmichael and Charles (1998, 2003). This paper will complement the latter and for the first time explore (a) the impact informal care has on labour market decisions and earning outcomes of hidden carers in Britain over time; (b) estimate hourly wages for non-carers and carers and decompose potential participation and wage gaps; and (c) derive opportunity costs of informal care from forgone wages and wage discrimination.

The paper is structured as follows. Section 2 will introduce the data set used in the analysis and present mean characteristics of the sample; Section 3 and 4 discusses the results for the participation decision and labour market earnings respectively; in Section 5 labour market related opportunity costs are estimated; Section 6 suggests potential policy implications.

\section{Data and Descriptives}

\section{$2.1 \quad$ Data and Definitions}

The analysis in this paper is based on data from the British Household Panel Study (BHPS) for the first 12 waves (1991-2002). Each year over 5,000 households consisting of roughly 10,000 individuals have been interviewed. The BHPS offers a wide range of variables and is nationally representative. For the purpose of our analysis only individuals who are aged 16 to 64 (59 for women), not working for the armed forces or in self employment and who have been interviewed in all consecutive waves have been included in the sample to create a balanced panel. ${ }^{4}$

The main group of interest are informal carers. Individuals are classified as carers if they answer one or both of the following questions with "yes":

\footnotetext{
${ }^{3}$ For a cost-benefit analysis of domiciliary care see Scottish Executive Central Research Unit (2002).

${ }^{4}$ While the overall panel of participating and non-participating individuals is balanced, individuals change their labour market status over time. Hence, the sub-sample of working individuals is unbalanced. However, as shown below attrition is not a major concern in the analysis.
} 
Is there anyone living with you who is sick, disabled or elderly whom you look after or give special help to?

Do you provide some regular service or help for any sick, disabled or elderly person not living with you?

Though the BHPS also contains information on benefit receipt and therefore on CA recipients, it undercounts the number of claimants. On average there are around 20 observations for CA recipients per year. Over the 12 waves their share among all informal carers varies from $1 \%$ to $5 \%$ percent with a clear positive trend over time. Clearly this is insufficient to derive any meaningful statistical inference or compare results with those of hidden carers.

A concern may be that CA recipients and hidden carers exhibit a very different set of personal and socioeconomic characteristics which renders a generalisation of the results in this paper problematic. For example CA claimants may care for more severely disabled people as they are eligible for Disability Living Allowance or Attendance Allowance; they may exhibit longer caring spells which makes it more likely that they have been in contact with social services and are aware of CA; they are less likely to participate in the labour market regardless of their current caring spell and are more willing to adhere to the imposed earnings limit when claiming CA.

Subject to the small number of observations and the main caveat that we have very little information about the person cared for, differences in characteristics between CA recipients and hidden carers in a pooled sample are very small. The main differences seem to be age, sex and the number of children. However, both the age distribution and gender 
split of CA recipients in the BHPS are inconsistent with administrative data from the Department for Work and Pensions. Apart from these inconsistencies and more seriously, the fact that CA recipients by definition are restricted in their labour market participation due the CA rules, any inclusion in a participation equation is likely to result in an endogeneity bias; hence, they have been removed from our sample.

\subsection{Characteristics of carers}

In Britain 14\% of working age individuals provide informal care for a sick, disabled or elderly person on a regularly basis. A typical care scenario is for a middle-aged woman to provide care for a parent or parent-in-law, who does not live in the same household as her, for fewer than four hours per week. However this masks the vast heterogeneity between carers and the burden of their responsibilities. Whilst just under half of all carers care for less than four hours per week, one in seven provide care for at least twenty hours and one in twenty carers for more than a hundred hours each week. Almost one in five carers regularly cares for more than one disabled person. ${ }^{5}$

It is most common for people to care for someone who does not live in the same household as them. The majority of carers (68\%) care for members of their immediate family, with more than half caring for a parent or parent-in-law. This remains true whether the carer is caring for one or more people. Differences can be observed between carers with lighter and more substantial caring responsibilities, principally in terms of the impact this has on their economic participation. For this reason carers are separated into two groups: those who participate in the labour market and those who do not. Individuals are said to participate if they did some paid work in the last week or did not but had a job

\footnotetext{
${ }^{5}$ Hours cared for is only an approximation of care intensity. For example, informal carers might purchase additional formal care to complement their caring responsibilities in which case few hours of caring may mask the true care intensity. Also note that Community Care Statistic (2003) defines intensive home care as more than 10 contact hours a week.
} 
that they were away from. ${ }^{6}$ The mean characteristics of carers and non-carers can be seen in table 2.

\section{< Table 2 about here $>$}

A number of differences arise in the characteristics of people who provide care and those who do not, and this is especially true in the inactive population. Carers have fewer qualifications than non-carers on average and lower wages when they are employed. Log hourly wages are constructed using information on the gross monthly wage before tax and other deductions in the current main job and information on the normal hours worked per week and paid overtime hours worked per week ${ }^{7}$. Wages are expressed in 1996 prices. It can be seen that carers who are in employment are more likely to work in the public sector than non-carers. This may be because public sector flexible working practices make it easier for carers to combine work with their caring responsibilities, whilst carers elsewhere may be forced to withdraw from economic activity whilst caring. There are also differences in the current labour market spell tenure. Carers exhibit on average longer spells of absence from the labour market compared to their non-caring counterparts. But once employed they have longer spells in the labour market, suggesting that carers are less mobile in general.

No differences are observed in the job satisfaction ${ }^{8}$ of carers and non-carers, though differences do emerge between the preferred working hours: $47 \%$ of carers who work full

\footnotetext{
${ }^{6}$ The coverage of the participation variable is not identical to the question on economic activity and there are fewer people declaring themselves employed as there should be according to the participation variable. ${ }^{7}$ The log hourly gross wage rate is defined as $w=\ln (\mathrm{Paygu} /(30 / 7)(\mathrm{Hs}+\alpha \mathrm{Hot}))$, where Paygu is the monthly gross pay in the current job, Hs is normal weekly hours, Hot is paid overtime hours per week and $\alpha$ is the overtime premium set to 1.5 .

${ }^{8}$ Individuals rate their job satisfaction overall and in terms of pay, hours worked and job security on a scale from 1 (very dissatisfied) to 7 (very satisfied). It can also be indicated whether they would like to increase, decrease or leave unaltered the number of hours they work.
} 
time wish to reduce the number of hours they work compared to 39\% of non-carers.

Clearly these findings are conditional on carers participating in the labour market, and carers with the heaviest care responsibilities have constraints on their ability to do this. ${ }^{9}$ This is highlighted in the difference in the economic activity of carers with substantial rather than lighter duties ${ }^{10}$ (see table 3). Nonetheless, even carers with relatively light duties experience disadvantage in the labour market.

\section{< Table 3 about here $>$}

Carers are more likely than their non-carer counterparts to be disabled themselves.

Following Burchardt (2003) individuals are identified as being disabled if they answer positively to the question "Does your health in any way limit your daily activities compared to most people of your age?"11 12 The incidence of disability amongst carers is $15 \%$ compared to $9 \%$ for non-carers. As a result this group may potentially be exposed to multiple labour market disadvantages.

\section{$<$ Figure 1 about here >}

\footnotetext{
${ }^{9}$ Unfortunately, hours cared for is categorical and also contains a group of carers who only state whether they cared for more or fewer than 20 hours a week. Hence, throughout the paper we can only distinguish these two groups.

${ }^{10}$ Defined as caring for more or less than 20 hours per week.

${ }^{11}$ Jenkins and Rigg (2003) define disabled individuals as those who answer "yes" to the question "Does your health limit the type of work or amount of work that you can do?” However, this variable is likely to be endogenous with regard to both labour market participation rates and wages.

${ }^{12}$ This question has not been asked in wave 9 and Jenkins and Rigg (2003) and Burchardt (2000) confine their studies to the first 8 waves. We have extrapolated the answer in the following manner to be able to use all 11 waves. If individuals are answering "yes" to "Does your health in any way limit your daily activities compared to most people of your age?" in the preceding and succeeding year (wave 8 or 10) it is assumed that they are also disabled in wave 9. Similarly, if they answer "no" in wave 8 and 10, it is assumed they would do so in wave 9 as well. In all other cases where answers differ in wave 8 and 10, if the answer is "yes" to the related wave 9 specific question "Being limited in the kind of work or other activities?" individuals are assumed to be disabled.
} 
Figure 1 depicts the share of informal carers among the working age population as well as the unconditional wage and participation differentials over time. While the proportion of carers has stayed remarkably constant between 1991 and 2002, both the overall wage and the participation gap have significantly increased. This is driven by a simultaneous increase in the participation of non-carers and a fall in the activity rate of carers. This may partly be due to ageing in our sample, as people become older they are more likely to encounter care responsibilities, and partly due to a buoyant labour market.

\subsection{The dynamics of caring}

In the BHPS between 1991 and 2002 55\% of working age adults did not spend any of the eleven years caring, $44 \%$ were carers in some periods but not in others and $1 \%$ cared for the entire period. The duration of caring spells is truncated from below and above. The conditional and unconditional average care spells were 1.8 and 3 years respectively. Furthermore, the share of individuals providing substantial amounts of care (20 hours or more) in our cohort has experienced a slight increase over time. Hirst (2002) finds a similar trend and shows that the cumulative risk of becoming an informal carer increases with age. This is also consistent with findings by the Department of Health (2003) that contact hours of home care services purchased or provided by Councils with Social Services Responsibilities in England have increased over time while the number of households receiving services has fallen. However, it is not clear whether this reduction is

demand or supply side driven. ${ }^{13}$ Finally, there is evidence that suggests that co-residential care is increasing while extra-residential care is decreasing over time. 
Informal carers have an up to 8 percentage points lower labour market participation rate compared to non-carers (Figure 1). Two questions arise: First, why do some carers participate while others do not and what are the determinants of this decision (intra gap). Secondly, what explains the higher participation rate of non-carers (inter gap).

\subsection{Intra participation gap}

\section{< Table 4 about here $>$}

Table 4 reports the results for four different regression models employing a populationaveraged approach (for the econometric model see Appendix A.). Model I and II estimate the pooled participation equations for non-carers and carers. Unsurprisingly, individuals are more likely to participate if they are older, non-disabled, male, have high education and no young children. While carers are significantly less likely to participate on average (t-value 9.45), regression results show that caring does not significantly reduce the likelihood of labour market participation after controlling for characteristics (Model I). This is not overly surprising given that the majority of carers have only limited care responsibilities. Yet, participation rates for carers caring for more than 20 hours a week are significantly reduced (Model II). These results show that negative impacts of caring on employment rates occur even below the current 35 hour cut-off point spelled out in the CA rules. One also needs to keep in mind that disadvantages are likely to occur on a

\footnotetext{
${ }^{13}$ One plausible explanation might be that service providers operate with fixed resources in the medium term and substitute intensity for coverage. This would also indicate that care needs are increasing over time.
} 
continuum. ${ }^{14}$ Carers providing help for fewer hours may well experience disadvantages which are not yet severe enough for them to drop out of the labour market or make them decide not to enter in the first place.

Model III estimates the same model for the sub-sample of carers and it is apparent that participation is driven by very much the same determinants. Model IV controls for a number of carer-specific variables such as the intensity of care (cared for 20+) and the type of person cared for (parent; spouse; child; other). ${ }^{15}$ Unsurprisingly, the more hours people care the less likely they are to work compared to individuals caring for less than 20 hours a week. On the other hand, caring for parents increases the likelihood of participation while looking after a spouse significantly reduces it. This might be partly explained by differences in the degree of choice. Caring for parents is more of a choice compared with looking after a spouse. It might also capture differences between coresidential and extra-residential care.

In order to see whether there are any gender differences among carers, table 5 reports results for males and females separately but for the same model specification as in table 4.

\section{$<$ Table 5 about here $>$}

A couple of points are worth pointing out. First, standard variables such as age and marital status yield very similar results for males and females. Second, results emphasise the importance of controlling for disability which exhibits a strong negative impact on the participation rate of carers. Third, educational attainment which did produce conclusive results in the overall regression yields very different results by gender. While for males a

\footnotetext{
${ }^{14}$ Carmichael and Charles (1998) try to determine threshold effects of various care types and find no such threshold for the participation equation but show that the wage is most strongly affected above the 20 hour cut-off.

${ }^{15}$ Note that these four categories are not mutually exclusive and hence have been included jointly.
} 
higher degree, degree and A-levels increase the likelihood of participation as one would expect, a higher degree has no effect on the labour market decision of female carers while lower degrees have. Fourth, children reduce the female participation rate significantly while it has no impact on males. This is especially the case in the presents of young kids. Fifth, table 5 shows that the overall positive effect of caring for parents is driven by males while caring for a spouse significantly reduces the participation rate of females only. Various other variables have been added to the model. For example we included the length of the current caring spell as a regressor. However, we found no evidence that the length of a caring spell significantly affects the likelihood of participation.

\subsection{Participation transitions}

One of the advantages of a balanced panel is that we are able to estimate conditional transitions between labour market states for any point in time keeping attrition to a minimum. Table 6 reports Markov transition matrices for two labour market states and four caring states in two time periods. Each cell contains the probability for an individual to move from state $j$ in $t-1$ to state $i$ in $t$, i.e. $\operatorname{Pr}(i \mid j)$. For example the second entry reports the probability of moving from participation into non-participation for an individual who has been caring in both $t-1$ and $t$. Each of these probabilities has been estimated by GEE based on the same set of characteristics that have been controlled for in table 5

\section{< Table 6 about here >}

There is remarkably little variation in estimated probabilities for transitions from work-towork (around 95\%) and work to non-participation (around 5\%) across carers and non- 
carers. Yet, there are substantial differences in transition probabilities from nonparticipation into another spell of non-participation and from non-participation into work between carers and non-carers. For example, someone who cares in the previous and current periods and did not participate in the labour market in $t-1$ has a $9 \%$ chance of moving into work in period $t$ compared to a $24 \%$ chance for a non-carer. Stopping caring increases the likelihood of participation significantly from $9 \%$ to $16 \%$. By the same token, carers in both periods have a 90\% likelihood of remaining out of work, while this is roughly 6\% points lower for someone who stops caring in $t$. Note however, that the data does not allow us to identify the end of the caring spell in relation to the participation state. $^{16}$

Table 7 reports conditional probabilities of moving between part-time and full-time employment. We find evidence that carers are both more likely to move from full-time into part-time and less likely to move from part-time into full-time.

\section{< Table 7 about here $>$}

\subsection{Decomposition of the intra participation gap}

In order to understand the driving factors of the intra participation gap, differences in the participation rates are decomposed using the methodology described in Appendix A. This is done for both all 12 cross sections and a longitudinal model for non-carers and carers respectively. Figures 2 to 7 and tables 8 to 10 show the results for the probit decompositions based on the set of regressors including age, sex, marital status, children

\footnotetext{
${ }^{16}$ For example for Pr(non-part | part, ct, nct-1) it might well be the case that an individual stops caring well before it stops working or vice versa. However, even though job related information is collected retrospectively in the BHPS for periods between two interviews, carers information is not.
} 
and education dummies, and disability status for the two different base categories $\left(\beta^{*}=\beta^{C}\right.$ or $\left.\beta^{*}=\beta^{N C}\right)$ separately.

\section{$<$ Figure 7 to 7 about here $>$ \\ < Table 8 to 10 about here >}

The difference in participation rates varies quite substantially over time, ranging from 3\% in 1992 to $8 \%$ in 1999. This highlights the importance of longitudinal as opposed to cross-sectional analysis. This is even more pronounced when broken down by gender. In the early 1990's the overall gap is mainly explained by differences in the estimated coefficients while more recently, a greater part of the gap can be explained by differences in the set of characteristics. However, the picture looks distinctively different by gender. The gap in labour participation for women can mainly be attributed to differences in coefficients with the exception of the early 1990’s. For men differences in observable characteristics explain a much greater fraction of the gap. Yet, for both sex these differences are not statistically significant. We also do not find evidence that a significant gender participation gap exists.

\section{$<$ Figure 9 and 10 about here $>$}

\section{< Table 11 about here >}

This changes in the longitudinal model (table 12). The participation gaps range from $2 \%$ for females to $8 \%$ for the inter-sex model and most differences are significant except for females. Even over time a large part of the gap can still be attributed to differences in 
coefficients rather than personal characteristics. This is particularly pronounced for the gender gap.

In the literature the explained and unexplained parts have been given varying interpretations. In general coefficients indicate how personal and socio-economic characteristics are translated into the probability of joining the labour market. On the one hand, they reflect the respective labour market structure and in the present context how well the specific needs of carers are met (demand side). To a great part this may include flexible working arrangements. On the other hand, however, they may also capture supply side effects of the formal care market. Hence, results suggest that even if the characteristics of non-carers and carers were very similar, carers would still be disadvantaged by either the labour market itself or by the formal care market. Examples of this may include shortages of formal care staff or high costs of residential care.

\subsection{Sample Selection}

Throughout this section we have assumed that carers are a random group and that neither endogeneity nor sample selection are present. However, Model I and II may suffer from endogeneity in the carers variable. For example, individuals with a low probability of participation due to some unobserved heterogeneity may decide to care instead causing causality to reverse. Yet, there is little or no literature on how to deal with endogeneity in panel probit models and given that two specifications are not crucial for the main purpose of the paper we do not explore the endogeneity problem any further. Instead, the analysis that will follow is based on separate equations for non-carers and carers in which case the endogeneity problem may translate into a sample selection issue. Using a Heckman (1979) approach for limited dependent variables we do not find any indication that the group of carers is a non-random sub-sample in the cross section except 
for two years. Identification of the carer equation is achieved by using information on household size given that most informal carers look after spouses or parents and parents in law.

In the panel case we adopt a method proposed for linear models by Verbeek and Nijman (1992) which amount to simple variable addition tests. Using a lagged carer dummy and a variable indicating the number of times an individual is counted as being a carer, we do not find evidence for sample selection in the panel model either.

\section{$4 \quad$ Earnings equations}

Once joined, informal carers may face further disadvantages in the labour market. In the following we will focus on earnings but this is not to say that other outcomes such as job mobility may not also be of great interest.

\section{<Table 13 about here >}

Table 13 reports the results for six different fixed effects estimations; in each case the dependent variable is the log hourly wage. Both the Hausman specification test and the Breusch and Pagan multiplier test indicate for every single model that there is unobserved heterogeneity which is correlated with observables. Using a fixed effects approach effaces this problem by de-meaning both dependent variable and regressors.

Various points are worth mentioning in table 13. First, and in line with the broader human capital theory, age, tenure, occupation, and firm size are important determinants of earnings though there are some exceptions. For example, labour market tenure does not impact significantly on earnings of carers despite them having longer than average 
tenure. ${ }^{17}$ This may reflect more static career profiles of informal carers. As normally the degree of flexibility regarding working arrangements is decreasing as individuals move up the career ladder, carers with a similar labour market spell tenure compared to non-carers may be on a flatter wage growth path. ${ }^{18}$

Second, caring clearly reduces hourly remuneration. Furthermore, care specific variables such as hours cared for and person cared for do not exhibit a significant impact. One reason might be that these characteristics are more decisive for the participation decision (see table 4) but once the first hurdle is negotiated do not exhibit an impact on wages. Unsurprisingly we find a significant reduction in wages the longer the care spell lasts (Care Duration). This again may be due to reduced upwards movement within occupations among carers. This result remains valid even when controlling for other care specific variables.

Somehow surprisingly, for both carers and non-carers part-time work seems to yield higher wages than full-time, other things equal. A possible interpretation for this result is that in the fixed effects model the part-time variable captures real switches between full and part-time by rendering the value of the dummy zero for time invariant observations, while the random effects and OLS model estimate the counterfactual effect of being in a part-time job. Estimating random effects and OLS models for the sub-group of switchers yields similar results while in the overall sample the part-time coefficient is negative in these models. This is also the case once the overtime premium is removed when transforming monthly earnings into hourly wages or when re-defining part-time as worked less than 30 hours per week without taking unpaid overtime into consideration. ${ }^{19}$ Using the latter definition of part-time it can also be shown that full-time employees work

\footnotetext{
${ }^{17}$ Note that tenure in our analysis is defined as years in the current labour market spell rather than current job as this information is not consistently available in the BHPS.

18 This assumes a strong correlation between labour market and job tenure.

${ }^{19}$ As a consequence the number of part-timers is increased.
} 
significantly more hours paid overtime compared to part-timers. Hence, it seems likely that the overtime premium for part-timers is higher than for full-time employees which would explain the positive impact of part-time in table 13.

\subsection{Decomposition of the wage gap}

Similar to the participation gap, the log hourly wage gap has been decomposed into overall, explained, and unexplained parts. Figures 10 to 15 depict the results for the two base categories. $^{20}$ The following variables have been included: Age, labour market tenure, education, children and occupation dummies, firm size, disability and marital status, sector, part-time, and time dummies were appropriate.

\section{< Figure 10 to 15 about here>}

Clearly, there is a great deal of volatility in the overall gap over the 12 years highlighting again the importance of panel analysis as opposed to cross-section studies. ${ }^{21}$ While the overall gap is negligible in the first half of the 1990's, it picks up momentum in the late 1990’s and reaches around 14\% in 1998 and 11\% in 2002. Comparing women and men it becomes apparent that the peak in the late 1990's has been due to a male wage gap while the female difference was rather small. The most recent divergence, however, is mainly driven by a female wage gap though the male gap is increasing slightly as well. Overall, there is a clear positive trend between 1991 and 2002 in earning differentials. A great part of the overall gap cannot be explained by differences in characteristics and results suggest that carers are systematically disadvantaged with respect to pay. This is

\footnotetext{
${ }^{20}$ Year specific earning differences are estimated using simple OLS. Again, potential sample selection issues are addressed by using Heckman's (1979) two stage approach. Results indicate that the selection bias is small and in most instances insignificant.

${ }^{21}$ Variability in wage gaps over time is a known phenomenon, see e.g. Gang and Yun (2001).
} 
different for females. Ignoring differences in the unexplained part, male carers would have earned more than their non-caring counterparts. For females, the result is less clearcut and reverts for the late 1990’s.

As one would expect from the inspection of figures 10 to 15, wage gaps are not significantly different from zero for most of the 1990's (tables 14 to 16). However, this changes in the late 1990’s.

\section{< Table 14 to 16 about here>}

Figures 16 and 17 and table 17 show the gender wage gap among informal carers.

Unsurprisingly, the general gender wage gap in the British labour market applies also to informal carers. ${ }^{22}$ However, table 17 shows that the gap among carers varies substantially depending on the base group though the trend is very similar and tends to be smaller than the gender gap among non-carers in most years. Bootstrapped confidence intervals show that all of the overall gaps are significantly different from zero. Furthermore, there is evidence that much of the gap is due to "discrimination”. Table 18 reports the same results using a panel model. Again, much of the differences are not explained by differences in characteristics.

As the wage gap has significantly increased in the late 1990's and can also be expected to be an increasing function of care intensity, table 19 and 20 report panel model results both for carers caring for more than 20 hours a week and for all carers in the years 1997-2002. Leaving gender gaps aside, pay differentials are substantially larger compared to panel results based on the entire 12 years. This is especially pronounced for carers spending more than 20 hours looking after sick, disabled, and elderly people. This group can expect

\footnotetext{
${ }^{22}$ For an overview of studies on the gender wage gap see e.g. Manning and Robinson (2004).
} 
to earn around $12 \%$ less compared to their non-caring or less intensively caring counterparts.

\section{< Table 19 and 20 about here $>$}

For males the gap rises to around $17 \%$. Note that a large part of the difference cannot be explained by differences in personal characteristics. Similarly, half of the overall gap for the years 1997 to 2002 is due to disadvantages in the labour market rather than differences in characteristics of individuals. Interestingly, the gender wage gap is reduced in both models which again combined with the separate results for males and females seems to suggest that males are disproportionately affected by caring responsibilities. Hence, since women are in general more likely to take up caring responsibilities than men, it appears crucial to control for informal care in models analysing gender pay differentials.

\subsection{Sample Selection}

Once again, throughout this section sample selection might be an issue. We have already established that the selection of carers in the overall sample is not driven by unobserved heterogeneity. Now, however, the selection of both carers and non-carers into the labour market might not be random. The classic example is the labour market participation of women (Heckman, 1979). Employing a fixed effects estimator will eliminate the time invariant part of this heterogeneity (Vella, 1998). However, using fixed effects will not cure for time varying unobserved heterogeneity which may cause biased estimators. Again, we make use of the methods proposed by Verbeek and Nijman (1992). Using the lagged participation dummy as an additional regressor in the fixed effects equations yields mixed results indicating some sample selection. However, Verbeek and Nijman (1992) 
acknowledge that their approach is lacking power as it merely tests for linear selection. Hence, we also use a method akin to Heckman’s (1979) two-step approach suggested by Wooldridge (1995) and estimate a pooled OLS regression with a “panel” inverse Mills ratio and robust standard errors. ${ }^{23}$ Again we find sample selection for a number of specifications. Wooldridge (1995) suggests a way of correcting for the bias. ${ }^{24}$ However, given the lack of theoretical underpinning of this model in the case of decomposition techniques and predicted wage gaps which were well outside the expected range of values when applying the Wooldridge estimation we decided not to correct for sample selection. Hence, results in Table 13 and Table 18 to Table 20 should be interpreted subject to this. ${ }^{25}$ We also control for sample selection in each of the year specific decompositions using Heckman's two step approach, yet we do not find evidence for non random sampling. Information on children is used to overcome the identification constraint in the selection equation.

\section{Opportunity costs}

Ultimately the question has to be how differences in the labour market participation rate and disadvantages in received wages translate into pecuniary disadvantages over time. In the case of non-participation these are forgone wages which would have otherwise been earned by the informal carer assuming that care is a driving force for the non-participation decision. In the case of earning differences the opportunity costs are the part of the wage difference between non-carers and carers which cannot be attributed to differences in productive characteristics.

\footnotetext{
${ }^{23}$ Wooldridge (1995) shows that the t-statistic is unaffected by the two-stage estimation however may have to be made robust against heteroskedasticity and serial correlation.

${ }^{24}$ See Vella (1998), and Kyriazidou (1997) for correction methodologies for sample selection in panel data.
} 
Carmicheal and Chareles (2003) estimate the former type of opportunity cost to amount to approximately $£ 615$ to $£ 1550$ a year. However, given the longitudinal nature of the BHPS it is possible to estimate costs of the total caring spell in the 12 years. In addition, we are also going to estimate opportunity costs due to wage penalties for informal carers using the results of the previous section.

Estimating forgone earnings requires counterfactual wages for those carers not working at a particular point in time. Hourly log wages for non-participants are predicted employing a generic wage model which includes age, martial status, gender, number of children, disability, education, as well as time dummies for the years 1991 to 2002. These are then converted into pounds and multiplied by the average weekly hours worked by employed individuals. Both wages and hours worked have been calculated based on results of noncarers (high scenario) and carers (low scenario). Finally, weekly earnings are converted into yearly wages and then summed over the relevant caring spells in the 12 years. The first two columns in table 21 summarise the gross costs of forgone wages. On average an individual who engages in informal care and does not work can expect to lose between $£ 33,000$ and $£ 26,000$ of labour income. ${ }^{26}$

\section{< Table 21 about here >}

Yet, the gross cost does not take into consideration the income saved by substituting informal for formal care. Studies by the Scottish Executive Central Research Unit (2001, 2002) estimated the hourly market value of informal care to range from $£ 7.50$ to $£ 9.24$. $^{27}$

\footnotetext{
${ }^{25}$ Given that we find sample selection for both non-carers and carers, in the best case the bias might average out when locking at the various differences in the decomposition. This is supported by the fact that the selection coefficients are of the same sign and roughly the same magnitude for the two groups. ${ }^{26}$ In 1996 prices.

${ }^{27}$ For the sake of simplicity hourly caring costs are assumed to stay constant of the 12 years. For more detail on unit costs of home care see e.g. Netten and Curtis (2002).
} 
Using the information on hours cared and the individual length of caring spells, net costs can be derived. ${ }^{28}$ Table 21 shows the net costs for the four scenarios. If replacement costs for informal care are low, the net costs of care are positive and vary between $£ 22,700$ and $£ 21,500$. If the hourly costs of caring increase to $£ 9.24$ the gain is significantly smaller. Hence, these results indicate that caring at the expense of labour market income is suboptimal from a monetary point of view. ${ }^{29}$

The above results, however, have to be interpreted with caution for a number of reasons. First, only those opportunity costs related to forgone wages have been considered. Yet, being out of the labour market has wider income implications. For example, while everyone with an entitlement or underlying entitlement for CA may receive National Insurance Credits this is not the case if informal carers fail to fulfil the CA criteria. This may be the case if they care for less than 35 hours a week as many of the carers in our sample do. Hence, the loss in today’s income will also negatively affect pension entitlements. Secondly, table 6 has shown, carers have a much lower probability of reentering the labour market once the caring spell has come to an end compared to noncarers. This may well reflect deteriorating human capital. Hence, the loss of wage income may last longer than the actual caring spell. Finally, the labour market participation decision can in general also be expected to be driven by the relative price of leisure. As we have shown in the previous section, it is not only non-participants who experience income disadvantages due to caring. Employed carers can expect to earn around 6\% less than non-carers. Approximately 2\% point of this difference can be explained by differences in personal characteristics (see table 18). The remainder of $4 \%$ points,

\footnotetext{
${ }^{28}$ The BHPS contains only information for the range of hours cared but the not the actual hours. For the purpose of the costings midpoints for 7 of the 9 different categories have been derived. For people reporting to carer for more than 100 hours a week the actual hours cared are assumed to be 100 . For carers with varying caring hours above 20 the actual hours are assumed to be 40 .

${ }^{29}$ Clearly this is ignoring any utility gains on the side of the individual cared for through more personalised care.
} 
however, can be interpreted as the wage penalty. Expressed in pounds per hour this amounts to roughly $£ 1.04$. The third column in table 21 shows that converting the hourly rate into yearly wages and summing over individual duration of caring spells yields a loss in income of around $£ 5,900$ over the caring spells in 12 years. ${ }^{30}$

\section{$6 \quad$ Conclusions and Policy Implications}

Informal care accounts for a large part of the overall social care market in Britain. More than $14 \%$ of working age individuals are caring for sick, disabled, and elderly relatives and friends. Around 76\% of all informal carers and 54\% of carers caring for more than 20 hours per week are combining work and caring responsibilities.

Using information from the first 12 waves of the BHPS, we study the effects of informal care on labour market participation and earnings outcomes over time. In particular, the paper is looking at intra and inter differences in labour market decisions among carers and between carers and non-carers. We find that the participation probability is a negative function of care intensity and is also significantly affected by the relationship between carer and the person cared for. While the former is mainly affecting the female labour market decision, the latter impacts upon males. We also find a significant inter gap in labour market participation of up to 8\%, much of which cannot be explained by differences in characteristics. Furthermore, there is evidence that unemployed or inactive carers have a substantial lower probability of entering the labour market once the caring spell draws to an end compared to their non-caring counterparts.

Secondly, we look at earning determinants and differences between non-carers and carers. Wages of carers are significantly lower than for non-carers and decreasing in the duration

\footnotetext{
${ }^{30}$ These costs are much larger once one predicts the life time loss. However, this will heavily on the assumptions on future employment and caring spells.
} 
of care. However, other care-specific variables exhibit no effect on wages which suggest that the impact is already been mitigated through the labour market participation decision. The overall wage gap between non-carers and carers for the 12 years is estimated to be around 6\%. Pay differences clearly increased in the late 1990’s, having been negligible in the first half of the decade. This is particularly the case for women. The overall pay gap for carers caring for more than 20 hours a week is twice as high. Again, much of this difference cannot be explained by differences in personal characteristics.

Finally, the paper derives approximate opportunity costs for those carers not participating and carers experiencing wage penalties in the labour market. Depending on the specification we find that opportunity costs due to forgone wages and wage penalties can be severe. Even when taking into account replacement costs of informal care findings suggest that providing care at the expanse of labour income does not pay. Several policy implications arise. Results in this paper provide evidence that informal carers are systematically disadvantaged when making decisions on whether to join or rejoin the labour force. A lack of flexible working arrangements, supply side shortages and the institutional infrastructure in the formal care market are likely to be the most important determinants that drive participation discrimination against carers. Currently, many of them are facing an all-or-nothing decision as to whether to enter the labour market and spend substantial amounts of income to purchase external care or, alternatively, sacrifice career prospects instead. This trade-off is likely to vary by place of residence as there are substantial differences in care provision among Local Authorities. This gap has widened further since 2002 when Scotland introduced free personal care of older people. Equally, unless informal carers are receiving other relevant benefits formal labour market support through job centres is currently limited and confined to CA recipients. 
Once entered, however, the double burden of work commitments and caring responsibilities reduces intra occupational mobility and, eventually, earning prospects, which is reflected in the significant unexplained wage gap we find. These problems are more severe the more intensive the care provided.

Ultimately it is down to the policy maker to agree on a socially optimal mix of formal and informal care and appropriate institutional arrangements to support either through supply and demand side policies. Clearly, any informed decision will have to take into account the entirety of costs involved, i.e. including opportunity costs. This paper argues that those costs exist and are substantial. Both the Department for Trade and Industry and the Prime Minister have recently acknowledged the need for flexible working arrangements for carers as evidence suggests that more time off and more flexible working hours for younger parents have been successful in rejoining them with the labour market. A similar approach will be needed to achieve a better balance between the positive and negative externalities of informal care. It also remains to be seen how the provision of free personal care in Scotland affects labour market outcomes of carers north of the Border. 
Appendix A. Econometric Model

In order to study the impact of informal care on the labour market participation and wages of individuals we will first estimate individual participation rates and wages both for each year and over all 12 waves and secondly decompose differences in these estimates into explained and unexplained components.

Let the participation equation be determined by

$$
P^{j_{i t}^{*}}=B_{i t}^{j} \gamma^{j}+u_{i t}^{j}
$$

where $P^{*}$ is a latent variable, $B$ the vector of characteristics, $\gamma$ the coefficient to be estimated and $u_{i}$ the error term which is assumed to be normally and independently distributed. In the following $i$ and $t$ refer to individual $i$ at time $t$. Equation (1) is estimated separately for non-carers $(j=N C)$ and carers $(j=C)$.

An individual will participate in the labour market if the expected utility of participation exceeds the gain of non-participation.

In general the latent variable is not observable and an index function is defined as follows:

$$
\begin{aligned}
& P^{j}{ }_{i t}=1 \text { if } P^{*}>0 \\
& P^{j}{ }_{i t}=0 \text { if } P^{*} \leq 0
\end{aligned}
$$

where $P_{i t}=1$ and $P_{i t}=0$ indicate labour market participation and non-participation respectively. While the cross section analysis will estimate simple probit models, the panel analysis will make use of a generalized estimating equations (GEE) approach by Zeger, Liang and Albert (1988) sometimes referred to as population averaged model. 
The log wage equation to be estimated over the 12 waves is

$\ln w^{j}{ }_{i t}=X_{i t}^{j} \beta^{j}+\varepsilon_{i t}^{j}$

where $\ln w_{i t}$ is the log hourly wage, $X_{i t}$ is a matrix of explanatory variables varying over both dimensions time and individual, and $\beta$ the vector of corresponding coefficients to be estimated.

The error term $\varepsilon_{i t}$ is defined as

$\varepsilon^{j}{ }_{i t}=\alpha^{j}{ }_{i}+\mu_{t}^{j}+u_{i t}^{j}$

where $\alpha_{i}$ is capturing unobservable individual characteristics which are constant over time but vary by individual (e.g. ability) and $\mu_{t}$ unobserved general characteristics which are constant over individuals but vary over time (eg interest rates). It is assumed that $u_{i t}$ is idiosyncratic and normally distributed. Yet, $\alpha_{i}$ and $\mu_{t}$ may be correlated with $X_{i t}$ so that $E\left[X_{i t} \alpha_{i}\right] \neq 0$ and $E\left[X_{i t} \mu_{t}\right] \neq 0$ which would lead to biased estimates of $\beta$. As the next section will show, this is indeed the case for our data and consequently a fixed effects model with time dummies has been estimated. Cross section wages for carers and noncarers are estimated by simple OLS.

The paramount aim of this paper is to explore differences in both participation rates and remuneration. Oaxaca (1973) has developed a convenient approach to split differences in estimated mean outcomes into parts that can be attributed to differences in characteristics (explained part) and differences which are due to differences in the estimated parameters (unexplained part). Following Jones and Makepeace (1996), in general terms this is 


$$
\begin{aligned}
\bar{Y}^{1}-\bar{Y}^{2} & =\left[1 / N_{1} \sum_{i=1}^{N_{1}} \Phi\left(Z_{i}^{1} \hat{\beta}^{1}\right)-1 / N_{2} \sum_{i=1}^{N_{2}} \Phi\left(Z_{i}^{2} \hat{\beta}^{1}\right)\right] \\
+ & {\left[1 / N_{2} \sum_{i=1}^{N_{2}} \Phi\left(Z_{i}^{2} \hat{\beta}^{1}\right)-1 / N_{2} \sum_{i=1}^{N_{2}} \Phi\left(Z_{i}^{2} \hat{\beta}^{2}\right)\right] }
\end{aligned}
$$

where $\bar{Y}$ is the estimated conditional variable under consideration (participation or wage) for group 1 (non carers) and group 2 (carers) respectively, $Z_{i}$ is the matrix of characteristics, $\hat{\beta}$ the vector of estimated coefficients for the two groups, $N$ is the number of respective observations and $\Phi$ any functional form. In the current context $\bar{Y}$ is either the estimated average participation rate or the estimated average log hourly wage. In the former $\Phi$ is the cumulative distribution function for a standard normal distribution, in the latter $\Phi$ is the simple linear function $X \hat{\beta} .^{31}$

The interpretation of equation (3) is very similar to the linear regression model decomposition pioneered by Oaxaca (1973). The term on the left-hand side is the difference in predicted participation rates or hourly wages between non-carers and carers. The first component in square brackets on the right-hand side is the difference in mean rates and wages due to differences in the characteristics of non-carers and carers. The second component captures the differences in mean predicted participation rates and wages due to differences in the estimated vector of coefficients $\hat{\beta}$. These are commonly referred to in the literature as “discrimination”. 32

\footnotetext{
${ }^{31}$ Note that $\hat{\beta}^{1}$ in the first term on the right hand side can equally be replaced by $\hat{\beta}^{2}$ and similarly, $Z_{i}^{2}$ in the second term can be replaced by $Z_{i}^{1}$. Both methods are equally valid and will in general produce different results. In the following results for both specification are presented $\hat{\beta}^{*}=\hat{\beta}^{C}$ and $\hat{\beta}^{*}=\hat{\beta}^{N C}$

${ }^{32}$ The term discrimination in the context of informal care is only meaningful if individuals willingly decide to provide care.
} 
One problem with this kind of decomposition technique is that we force the sets of regressors for the two groups to be the same in order to be able to produce out-of-sample predictions. As will become apparent in the next section, participation and earnings equations for carers may be driven by a larger set of characteristics which are not observable for non-carers. For example, for carers we observe the hours cared for or the place of care. However, these characteristics are by definition not available for non-carers. Regressing on only a subset of regressors may produce biased and inconsistent estimators if the excluded variables are correlated with the included regressors. In other words, we may face an omitted variable problem.

In order to test for correlation between carer specific and general regressors we have compared pair wise correlation coefficients. However, few of them were significantly different from zero with an average correlation of around 5\%. None were larger than 18\%. Correlation is even less of a concern when broken down by gender. Hence, any potential omitted variable bias can be expected to be very small especially when looking at average effects as in equation (3).

Standard errors for the point estimates in (3) are naturally not available. In order to make statistical inference possible, bootstrap confidence intervals will be estimated using a simple re-sampling method (see Efron and Tibshirani, 1993 for details). This is, 500 samples of size $N$ are drawn from the original sample (parent sample) with replacement. 
For each sample all statistics are re-estimated and then used to derive standard errors and confidence intervals. ${ }^{33}$

\footnotetext{
${ }^{33}$ Three different types of intervals have been calculated, the normal $(\mathrm{N})$, the percentile $(\mathrm{P})$ and the bias correct (BC). If the bootstrap statistics are roughly normally distributed, the normal and percentile intervals will be fairly similar. However, if there are significant differences, percentile intervals are usually preferred. Furthermore, the point estimate of the original sample and the average statistic of the bootstrap do not necessarily agree and their difference is referred to as bias. Then, the bias correct confidence interval takes these possible discrepancies into account. If the bias is small, percentile and bias corrected confidence intervals are roughly identical. Hence, all three intervals will be very similar for an approximately normally distributed bootstrap statistic and a small bias. If not otherwise stated, significance levels refer to all three methods.
} 
References:

Burchardt, T., 2003. Being and becoming: Social exclusion and the onset of disability. CASE Report 21, London School of Economics.

Carmichael, F., Charles, S., 1998. The labour market costs of community care. Journal of Health Economics 17 (6), 747-765.

Carmichael, F., Charles, S., 2003. The opportunity costs of informal care: does gender matter? Journal of Health Economics 22 (5), 781-803.

Child Poverty Action Group, 2004. Welfare benefits and tax credits handbook 2004/2005. London

Department for Work and Pensions, 2003. Factors affecting the labour market performance of older workers. Research Report 200, London.

Department of Health, 1999. The National Strategy for Carers, http://www.carers.gov.uk/pdfs/care.pdf

Department of Health, 2003. Community Care Statistics 2003: Home care services, England, http://www.publications.doh.gov.uk/public/Hh12003.pdf

Efron, B., Tibshirani, R.,J., 1993. An Introduction to the Bootstrap. Chapman and Hall, New York

Evandrou, M., 1995. Employment and care, paid and unpaid work: The socio-economic position of informal cares in Britain, in: Phillips, J. (Ed.), Working Carers, Avebury, Aldershot.

Gang, I. N., Yun, M.-S., 2001. The Gender Wage Gap and Discrimination, East Germany 1990-1997. Vierteljahrshefte zur Wirtschaftsforschung, 70/1. 
Heckman, J., 1979. Sample Selection Bias as a Specification Error. Econometrica 47(1), 153-162.

Hirst, M., 2002. Transition to informal carer in Great Britain during the 1990's. Journal of Epidemiology and Community Health 56, 579-587.

Jenkins, S., Rigg, J., 2000. Disability and Disadvantage: selection, onset and duration effects. Institute for Social and Economic Research working paper no. 2003-18, Colchester, University of Essex.

Jones, D.R., Makepeace, G.H., 1996. Equal Worth, Equal Opportunities: Pay and Promotion in an Internal Labour Market. The Economic Journal 106 (March), 401-409.

Kyriazidou, E., 1997. Estimation of a panel data sample selection model. Econometrica $65,1335-1364$.

Laing and Buisson, 2002. UK Domiciliary Care Markets 2002. Fifth Edition, Laing \& Buisson, London.

Laing and Buisson, 2003. Care of elderly people. Sixteenth Edition, Laing \& Buisson, London.

Manning, A., Robinson, H., 2004. Something in the Way She Moves: A Fresh Look at an Old Gap. forthcoming in Oxford Economic Papers.

Netten, A., Curtis, L., 2002. Unit Costs of Health and Social Care. Personal Social Services Research Unit, University of Kent at Canterbury.

Oaxaca, R.L., 1973. Male-Female Wage Differentials in Urban Labor Markets. International Economic Review 14 (1), 693-709.

ONS, 2002. Carers 2000. Office for National Statistics, London. 
Scottish Executive Central Research Unit, 2001. Providing Free Personal Carer for Older People: Research Commissioned to Inform the Work of the Care Development Group. Edinburgh.

Scottish Executive Central Research Unit, 2002. Over the Threshold? An Exploration of Intensive Domiciliary Support for Older People. Edinburgh.

Vella, F. 1998. Estimating Models with Sample Selection Bias: A Survey. Journal of Human Resources Winter,127-169.

Verbeek, M., Nijman, T., 1992. Testing for selectivity bias in panel data models. International Economic Review 33, 681-703.

Wooldridge, J.M., 1995. Selection corrections for panel data models under conditional mean independence assumptions. Journal of Econometrica 68, 115-132.

Zeger, S.L., Liang, K.-Y., Albert, P. S., 1988. Models for Longitudinal Data: A Generalized Estimation Equation Approach. Biometrics 44, 1049-1060. 
Tables and Figures

Table 1: Date description

\begin{tabular}{|ll|}
\hline Variable & Description \\
\hline Dependent Variables: & \\
Participation rate & $(1,0)$ if participating in the labour market \\
Log hourly wage & Log of hourly wage (overtime adjusted) \\
Independent Variables: & Age of individual \\
Age & Squared age of individual \\
Age sq & $(1,0)$ if individual is male \\
Male & $(1,0)$ if individual is disabled \\
Disabled & $(1,0)$ if individual is married \\
Married & $(1,0)$ qualification dummy \\
Higher degree & $(1,0)$ qualification dummy \\
Degree & $(1,0)$ qualification dummy \\
A-level & $(1,0)$ qualification dummy \\
O-level and below & $(1,0)$ children dummy \\
Children 0-4 & $(1,0)$ children dummy \\
Children 5-11 & $(1,0)$ children dummy \\
Children 11-15 & $(1,0)$ if individual is informal carer \\
Carer & $(1,0)$ if cared for more than 20 hours a week \\
Cared 20+ & Current care spell lengths \\
Care Duration & $(1,0)$ if individual carers for Spouse \\
Cared for Spouse & $(1,0)$ if individual cares for parent or parent in law \\
Cared for Parent & $(1,0)$ if individual cares for Children \\
Cared for Children & $(1,0)$ if individual cares for others \\
Cared for Other & $(1,0)$ if individual works less than 30 hrs \\
Part-time & $(1,0)$ if individual works in the public sector \\
Public & $(1,0)$ occupation dummy \\
Professional & $(1,0)$ occupation dummy \\
Managerial & $(1,0)$ occupation dummy \\
Skilled non-manual & $(1,0)$ occupation dummy \\
Skilled manual & Years in current labour market spell \\
Tenure & Squared of tenure \\
Tenure sq & Firm with less than 49 employees \\
Small & Firm with more than 50 but less than 500 \\
Medium & employees \\
\hline & \\
\hline
\end{tabular}


Table 2: Mean characteristics, BHPS 1991-2002

\begin{tabular}{|c|c|c|c|c|c|c|c|c|}
\hline & \multicolumn{4}{|c|}{ Non-participant } & \multicolumn{4}{|c|}{ Participants } \\
\hline & \multicolumn{2}{|l|}{ Non-carer } & \multicolumn{2}{|l|}{ Carer } & \multicolumn{2}{|c|}{ Non-carer } & \multicolumn{2}{|l|}{ Carer } \\
\hline & Mean & Std. dev. & Mean & Std. dev. & Mean & Std. dev. & Mean & Std. dev. \\
\hline Log wage & & & & & 1.9342 & 0.5535 & 1.8762 & 0.5584 \\
\hline Age & 38.97 & 11.86 & 44.56 & 10.91 & 38.11 & 9.73 & 43.27 & 9.15 \\
\hline Male & 0.3004 & 0.4585 & 0.3442 & 0.4753 & 0.4797 & 0.4996 & 0.4146 & 0.4927 \\
\hline Disabled & 0.2617 & 0.4396 & 0.3511 & 0.4775 & 0.0533 & 0.2246 & 0.0917 & 0.2887 \\
\hline Married & 0.6279 & 0.4834 & 0.7564 & 0.4295 & 0.6648 & 0.4721 & 0.7372 & 0.4402 \\
\hline Higher Degree & 0.0157 & 0.1245 & 0.0089 & 0.0938 & 0.0299 & 0.1704 & 0.0216 & 0.1453 \\
\hline Degree & 0.1160 & 0.3203 & 0.0858 & 0.2802 & 0.2132 & 0.4096 & 0.1604 & 0.3670 \\
\hline A-level & 0.1636 & 0.3700 & 0.1351 & 0.3420 & 0.2146 & 0.4105 & 0.1956 & 0.3967 \\
\hline O-level and below & 0.3687 & 0.4825 & 0.3925 & 0.4885 & 0.3720 & 0.4833 & 0.3855 & 0.4868 \\
\hline None & 0.3359 & 0.4723 & 0.3777 & 0.4851 & 0.1703 & 0.3759 & 0.2369 & 0.4253 \\
\hline Children 0-4 & 0.2727 & 0.4454 & 0.1460 & 0.3532 & 0.1498 & 0.3569 & 0.0738 & 0.2615 \\
\hline Children 5-11 & 0.3480 & 0.4764 & 0.2761 & 0.4473 & 0.2588 & 0.4380 & 0.2066 & 0.4049 \\
\hline Children 11-15 & 0.1648 & 0.3711 & 0.1972 & 0.3981 & 0.1750 & 0.3800 & 0.1935 & 0.3951 \\
\hline London & 0.0168 & 0.1284 & 0.0207 & 0.1425 & 0.0231 & 0.1502 & 0.0198 & 0.1394 \\
\hline Cared 20+ & & & 0.2114 & 0.4085 & & & 0.0996 & 0.2995 \\
\hline Cared for Spouse & & & 0.4911 & 0.5002 & & & 0.5717 & 0.4949 \\
\hline Cared for Parent & & & 0.1302 & 0.3367 & & & 0.0635 & 0.2439 \\
\hline Cared for Children & & & 0.1134 & 0.3173 & & & 0.0495 & 0.2170 \\
\hline Cared for Other & & & 0.3028 & 0.4597 & & & 0.3235 & 0.4679 \\
\hline Part-time & & & & & 0.2038 & 0.4029 & 0.2489 & 0.4324 \\
\hline Public & & & & & 0.2872 & 0.4525 & 0.3393 & 0.4735 \\
\hline Professional & & & & & 0.0605 & 0.2385 & 0.0353 & 0.1846 \\
\hline Managerial & & & & & 0.3406 & 0.4739 & 0.3302 & 0.4704 \\
\hline Skilled non-manual & & & & & 0.2672 & 0.4425 & 0.2578 & 0.4375 \\
\hline Skilled manual & & & & & 0.1715 & 0.3770 & 0.1841 & 0.3876 \\
\hline Tenure & 6.0866 & 6.6748 & 7.4474 & 7.8497 & 4.8924 & 5.6535 & 6.1390 & 6.4174 \\
\hline Small & & & & & 0.4414 & 0.4966 & 0.4617 & 0.4986 \\
\hline Medium & & & & & 0.3797 & 0.4853 & 0.3790 & 0.4852 \\
\hline $\mathrm{N}$ & 5017 & & 1014 & & 21362 & & 3292 & \\
\hline
\end{tabular}


Table 3: Economic activity breakdown by hours caring

\begin{tabular}{lllll}
\hline & \multicolumn{3}{c}{ Carers } \\
& Non-carer & All carers & $<20 \mathrm{hrs}$ & $>20 \mathrm{hrs}$ \\
\hline Employed & $80.7 \%$ & $76.2 \%$ & $78.7 \%$ & $60.3 \%$ \\
Unemployed & $3.3 \%$ & $3.8 \%$ & $3.1 \%$ & $7.5 \%$ \\
Inactive & $16.0 \%$ & $20.0 \%$ & $18.2 \%$ & $32.1 \%$ \\
Total & $100.0 \%$ & $100.0 \%$ & $100.0 \%$ & $100.0 \%$ \\
\hline
\end{tabular}

Figure 1: Unconditional non carer/carer wage and participation gap, \% of carers (1991-2002)

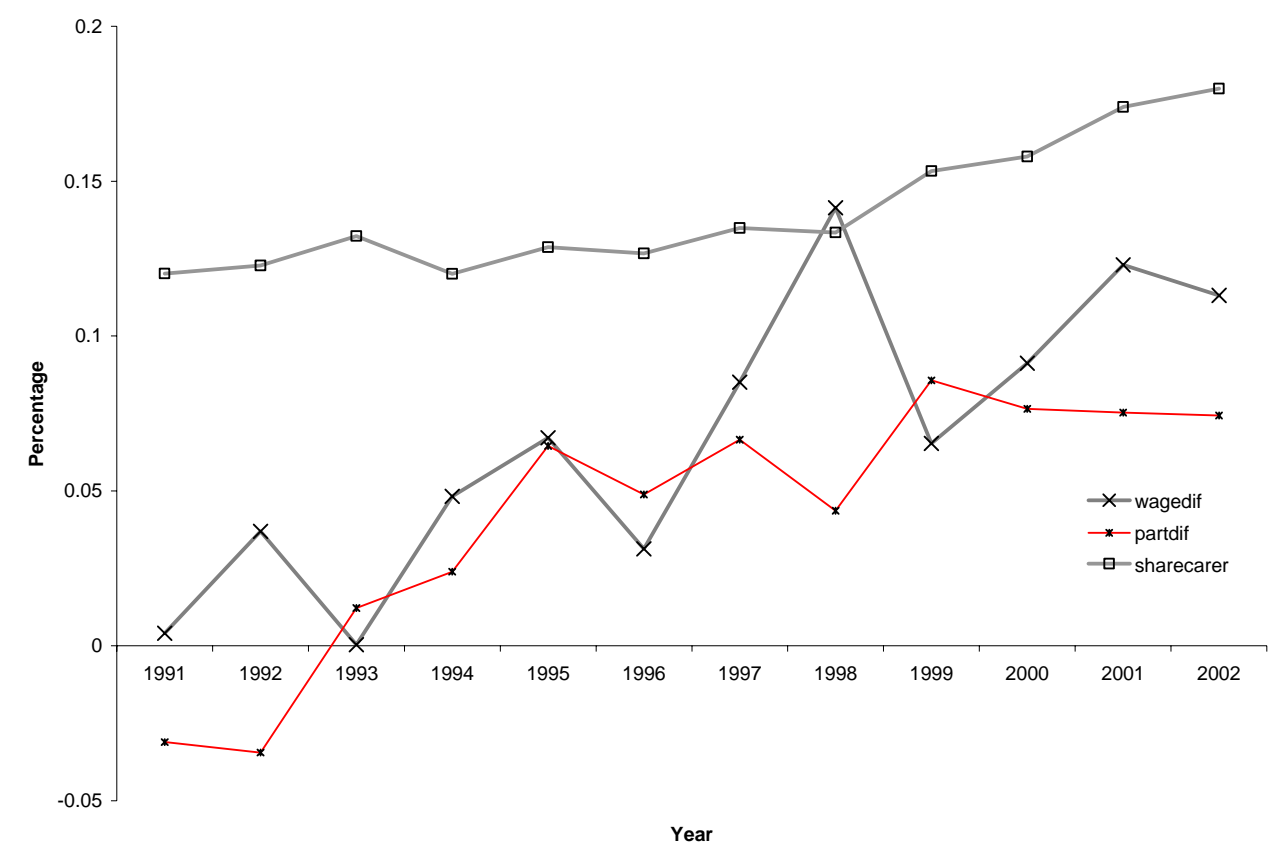


Table 4: GEE estimation results of labour market participation decision, BHPS 1991-2002

\begin{tabular}{|c|c|c|c|c|c|c|c|c|}
\hline & \multicolumn{2}{|l|}{ Model I } & \multicolumn{2}{|l|}{ Model II } & \multicolumn{2}{|c|}{ Model III } & \multicolumn{2}{|l|}{ Model IV } \\
\hline & Coeff & z-value & Coeff & z-value & Coeff & z-value & Coeff & z-value \\
\hline Constant & -2.8473 & $-12.50 * *$ & -2.7773 & $-5.61 * *$ & -2.7018 & $-5.41 * *$ & -2.6547 & $-5.23 * *$ \\
\hline Age & 0.1946 & $15.71^{* *}$ & 0.1968 & $7.97 * *$ & 0.1929 & $7.67 * *$ & 0.1877 & $7.52 * *$ \\
\hline Age Sq & -0.0028 & $-15.50 * *$ & -0.0026 & $-8.59 * *$ & -0.0025 & $-8.29 * *$ & -0.0025 & $-8.16^{* *}$ \\
\hline Male & 0.5525 & $7.44 * *$ & 0.4037 & $5.16^{* *}$ & 0.4213 & $5.37 * *$ & 0.4207 & $5.23 * *$ \\
\hline Disabled & -0.4755 & $-8.22 * *$ & -0.4188 & $-5.83^{* *}$ & -0.4017 & $-5.50 * *$ & -0.4085 & $-5.71 * *$ \\
\hline Married & 0.0489 & 1.17 & 0.0589 & 0.82 & 0.0409 & 0.58 & 0.0856 & 1.18 \\
\hline Higher degree & 1.1010 & $4.63^{* *}$ & 0.3816 & $1.88^{*}$ & 0.3837 & $1.99 * *$ & 0.3790 & $1.89 *$ \\
\hline Degree & 0.7047 & $8.21 * *$ & 0.6156 & 4.03 & 0.6285 & 4.07 & 0.5965 & $3.81 * *$ \\
\hline A-level & 0.1842 & $2.43^{* *}$ & 0.3594 & $2.76^{* *}$ & 0.3865 & $2.96 * *$ & 0.3704 & $2.86 * *$ \\
\hline O-level and below & 0.2661 & $3.85^{* *}$ & 0.2068 & $2.15^{* *}$ & 0.2168 & $2.27 * *$ & 0.2086 & $2.16^{* *}$ \\
\hline Children 0-4 & -0.4393 & $-9.98 * *$ & -0.3738 & $-4.41 * *$ & -0.3755 & $-4.49 * *$ & -0.3802 & $-4.56 * *$ \\
\hline Children 4-11 & -0.2328 & $-8.10 * *$ & -0.2829 & $-3.73^{* *}$ & -0.2710 & $-3.57 * *$ & -0.2834 & $-3.72 * *$ \\
\hline Children 12-15 & -0.0041 & -0.13 & -0.0459 & -0.66 & -0.0303 & -0.43 & -0.0463 & -0.68 \\
\hline Carer & 2.5390 & 1.36 & & & & & & \\
\hline Cared 20+ & & & -0.1642 & $-2.84 * *$ & & & -0.1358 & $-2.27 * *$ \\
\hline Cared for Parent & & & & & & & 0.1190 & $1.77^{*}$ \\
\hline Cared for Spouse & & & & & & & -0.2964 & $-2.41 * *$ \\
\hline Cared for Child & & & & & & & -0.0327 & -0.24 \\
\hline Cared for other & & & & & & & -0.0177 & -0.29 \\
\hline Time Dummies & Yes & & Yes & & Yes & & Yes & \\
\hline VN selection significant & - & & - & & No & & No & \\
\hline $\mathrm{N}$ & 30685 & & 30685 & & 4306 & & 4182 & \\
\hline Pr $>$ Wald-Chi2 & 0.0000 & & 0.0000 & & 0.0000 & & 0.0000 & \\
\hline
\end{tabular}


Table 5: GEE results of labour market participation decision CARER, BHPS 1991-2002

\begin{tabular}{|c|c|c|c|c|c|c|c|c|}
\hline & \multicolumn{2}{|l|}{ Male } & \multicolumn{2}{|l|}{ Male } & \multicolumn{2}{|l|}{ Female } & \multicolumn{2}{|l|}{ Female } \\
\hline & Coeff & z-value & Coeff & z-value & Coeff & z-value & Coeff & z-value \\
\hline Constant & -2.6542 & $-3.45 * *$ & -2.5865 & $-3.27 * *$ & -2.2078 & $-3.35 * *$ & -2.2196 & $-3.27 * *$ \\
\hline Age & 0.2263 & $6.08^{* *}$ & 0.2211 & $5.65 * *$ & 0.1593 & $4.64^{* *}$ & 0.1548 & $4.44 * *$ \\
\hline Age Sq & -0.0031 & $-7.03 * *$ & -0.0031 & $-6.55^{* *}$ & -0.0020 & $-4.73 * *$ & -0.0020 & $-4.55 * *$ \\
\hline Disabled & -0.3600 & $-2.46^{* *}$ & -0.3607 & $-2.33^{* *}$ & -0.4642 & $-5.50 * *$ & -0.4460 & $-5.26 * *$ \\
\hline Married & 0.1474 & 1.16 & 0.0797 & 0.61 & 0.0034 & 0.04 & 0.0598 & 0.67 \\
\hline Higher degree & 0.4568 & $1.63^{*}$ & 0.3988 & 1.41 & 0.3119 & 1.03 & 0.2890 & 0.95 \\
\hline Degree & 0.5728 & $2.21^{* *}$ & 0.6049 & $2.39 * *$ & 0.6921 & $3.38 * *$ & 0.6521 & $3.05 * *$ \\
\hline A-level & 0.4477 & 1.59 & 0.5164 & $1.91^{*}$ & 0.3646 & $2.64 * *$ & 0.3463 & $2.49 * *$ \\
\hline O-level and below & 0.0967 & 0.44 & 0.0910 & 0.42 & 0.2736 & $2.52 * *$ & 0.2581 & $2.33^{* *}$ \\
\hline Children 0-4 & 0.2690 & 1.36 & 0.2538 & 1.35 & -0.5658 & $-5.89 * *$ & -0.5674 & $-5.93 * *$ \\
\hline Children 4-11 & -0.1954 & -1.25 & -0.2030 & -1.23 & -0.3207 & $-3.63 * *$ & -0.3210 & $-3.57 * *$ \\
\hline Children 12-15 & 0.1665 & 0.74 & 0.1594 & 0.71 & -0.0978 & -1.53 & -0.0915 & -1.46 \\
\hline Cared for Parent & & & 0.2162 & $1.72 *$ & & & 0.1291 & 1.59 \\
\hline Cared for Spouse & & & 0.1474 & 0.78 & & & -0.5543 & $-3.70 * *$ \\
\hline Cared for Child & & & 0.1988 & 0.55 & & & -0.2114 & -1.47 \\
\hline Cared for other & & & -0.0706 & -0.59 & & & 0.0859 & 1.25 \\
\hline Time Dummies & Yes & & Yes & & Yes & & Yes & \\
\hline VN selection significant & No & & No & & No & & No & \\
\hline $\mathrm{N}$ & 1714 & & 1714 & & 2592 & & 2592 & \\
\hline Pr>Wald-Chi2 & 0.0000 & & 0.0000 & & 0.0000 & & 0.0000 & \\
\hline
\end{tabular}

Note: **indicates $95 \%$ significance level, * indicates $90 \%$ significance level. 
Table 6: Markov participation transition matrix, BHPS 1991-2002

\begin{tabular}{|c|c|c|c|}
\hline $\begin{array}{l}\operatorname{Pr}(\text { part } \mid \text { part, ct, ct- } 1 \text { ) } \\
\operatorname{Pr}(\text { non-part } \mid \text { part, ct, ct- } 1 \text { ) }\end{array}$ & $\begin{array}{l}\operatorname{Pr}(\text { part } \mid \text { non-part, ct, ct-1) } \\
\text { Pr(non-part } \mid \text { non-part, ct, ct-1) }\end{array}$ & $\begin{array}{l}95.69 \% \\
4.31 \% \\
\end{array}$ & $\begin{array}{l}9.54 \% \\
90.46 \% \\
\end{array}$ \\
\hline $\begin{array}{l}\text { Pr(part | part, ct, nct-1) } \\
\text { P(non-part | part, ct, nct-1) }\end{array}$ & $\begin{array}{l}\operatorname{Pr}(\text { part | non-part, ct, nct-1) } \\
\text { Pr(non-part | non-part, ct, nct-1) }\end{array}$ & $\begin{array}{l}95.21 \% \\
4.79 \%\end{array}$ & $\begin{array}{l}16.61 \% \\
83.39 \%\end{array}$ \\
\hline $\begin{array}{l}\operatorname{Pr}(\text { part | part, nct, ct-1) } \\
\operatorname{Pr}(\text { non-part | part, nct, ct-1) }\end{array}$ & $\begin{array}{l}\operatorname{Pr}(\text { part | non-part, nct, ct-1) } \\
\text { Pr(non-part | non-part, nct, ct-1) }\end{array}$ & $\begin{array}{l}99.52 \% \\
0.48 \% \\
\end{array}$ & $\begin{array}{l}15.95 \% \\
84.05 \% \\
\end{array}$ \\
\hline $\begin{array}{l}\operatorname{Pr} \text { (part | part, nct, nct-1) } \\
\text { Pr(non-part | part, nct, nct-1) }\end{array}$ & $\begin{array}{l}\operatorname{Pr}(\text { part } \mid \text { non-part, nct, nct-1) } \\
\operatorname{Pr}(\text { non-part } \mid \text { non-part, nct, nct-1) }\end{array}$ & $\begin{array}{l}95.11 \% \\
4.89 \% \\
\end{array}$ & $\begin{array}{l}24.46 \% \\
75.54 \% \\
\end{array}$ \\
\hline
\end{tabular}

Note: Probabilities are predicted using a GEE probit model controlling for various personal characteristics.

Table 7: Markov part-time/fulltime transition matrix, BHPS 1991-2002

\begin{tabular}{|ll|ll|}
\hline $\operatorname{Pr}(\mathrm{pt} \mid \mathrm{ft}, \mathrm{ct}, \mathrm{ct}-1)$ & $\operatorname{Pr}(\mathrm{pt} \mid \mathrm{pt}, \mathrm{ct}, \mathrm{ct}-1)$ & $4.44 \%$ & $87.34 \%$ \\
$\operatorname{Pr}(\mathrm{ft} \mid \mathrm{ft}, \mathrm{ct}, \mathrm{ct}-1)$ & $\operatorname{Pr}(\mathrm{ft} \mid \mathrm{pt}, \mathrm{ct}, \mathrm{ct}-1)$ & $95.56 \%$ & $12.66 \%$ \\
\hline \multicolumn{3}{l}{} & \\
\hline $\operatorname{Pr}(\mathrm{pt} \mid \mathrm{ft}, \mathrm{nct}, \mathrm{nct}-1)$ & $\operatorname{Pr}(\mathrm{pt} \mid \mathrm{pt}, \mathrm{nct}, \mathrm{nct}-1)$ & $3.62 \%$ & $80.73 \%$ \\
$\operatorname{Pr}(\mathrm{ft} \mid \mathrm{ft}, \mathrm{nct}, \mathrm{nct}-1)$ & $\operatorname{Pr}(\mathrm{ft} \mid \mathrm{pt}, \mathrm{nct}, \mathrm{nct}-1)$ & $96.38 \%$ & $19.27 \%$ \\
\hline
\end{tabular}

Note: Probabilities are predicted using a GEE probit model controlling for various personal characteristics. 
Figure 2: Estimated participation gap, non-carers/cares, overall $\beta^{*}=\beta^{C}$

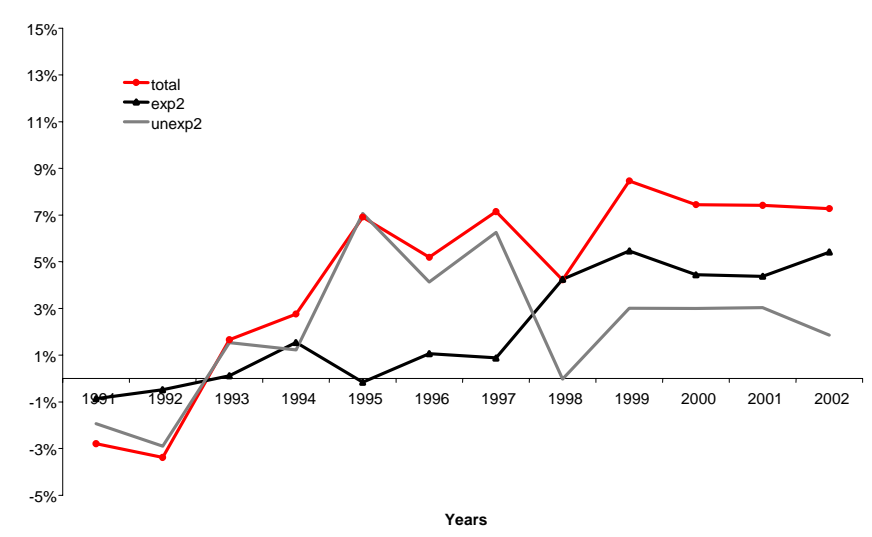

Figure 4: Estimated participation gap, non-carers/cares, males $\beta^{*}=\beta^{C}$

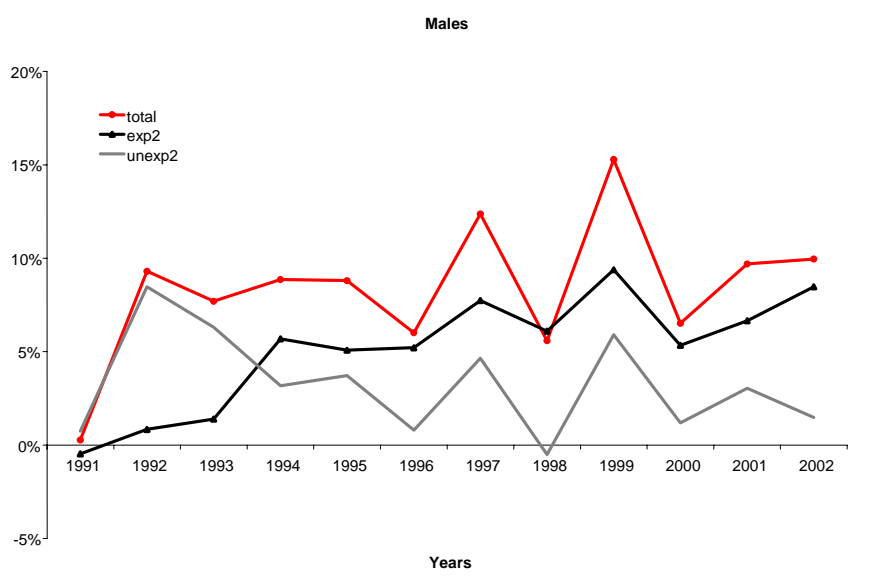

Figure 3: Estimated participation gap, non-carers/cares, overall $\beta^{*}=\beta^{N C}$

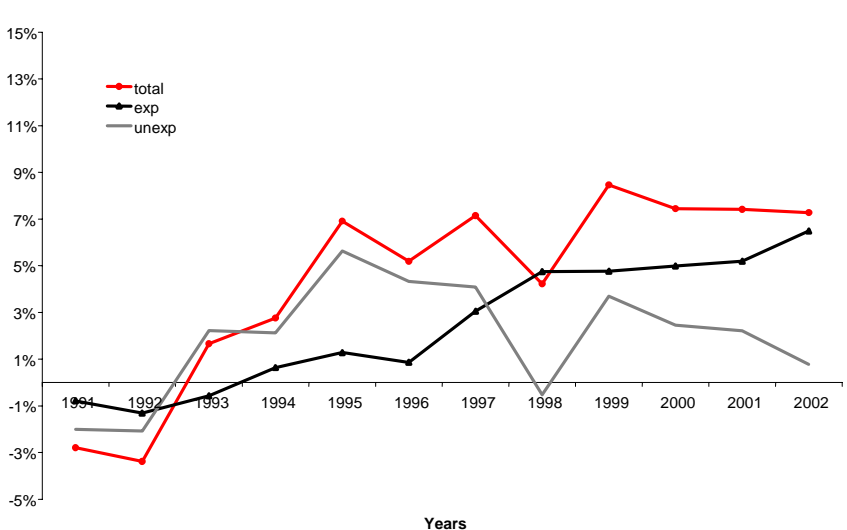

Figure 5: Estimated participation gap, non carers/carers, males $\beta^{*}=\beta^{N C}$

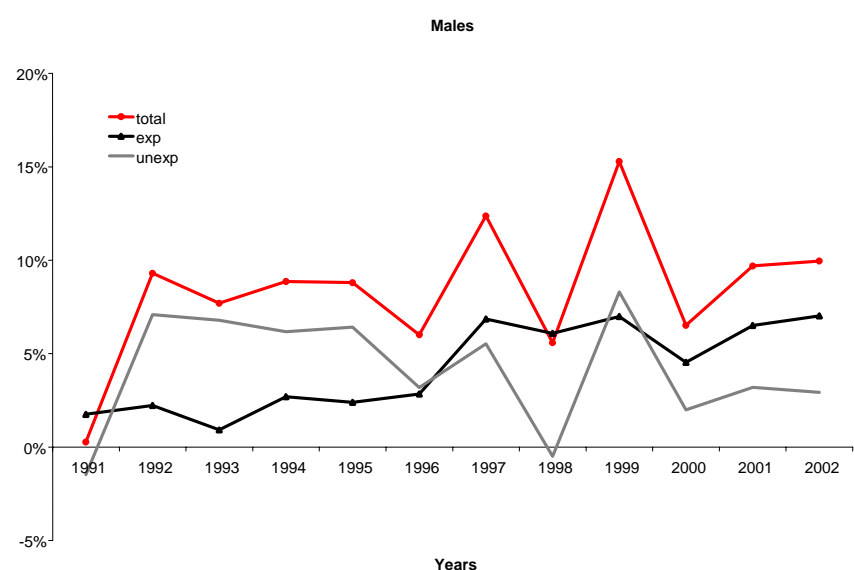


Figure 6: Estimated participation gap, non-carers/cares, females $\beta^{*}=\beta^{C}$

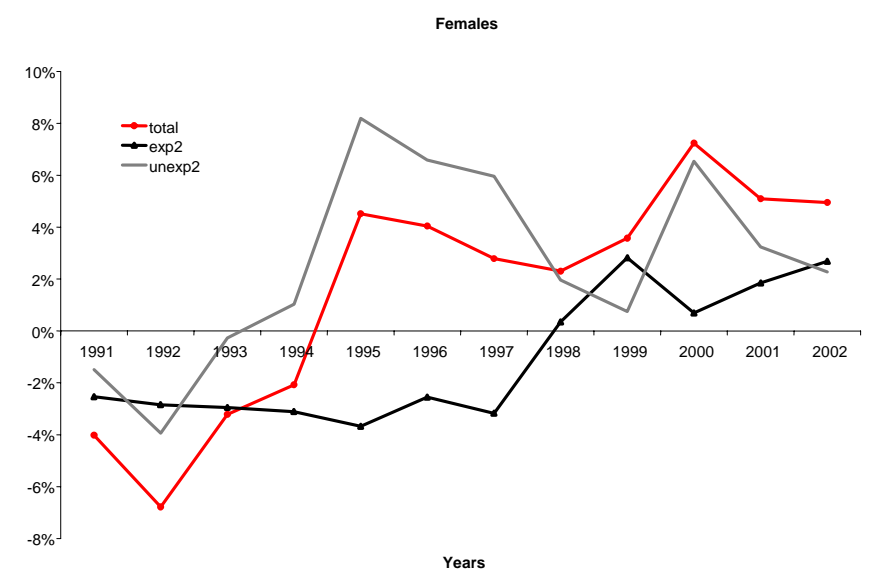

Figure 8: Estimated participation gap, male/female $\beta^{*}=\beta^{F}$

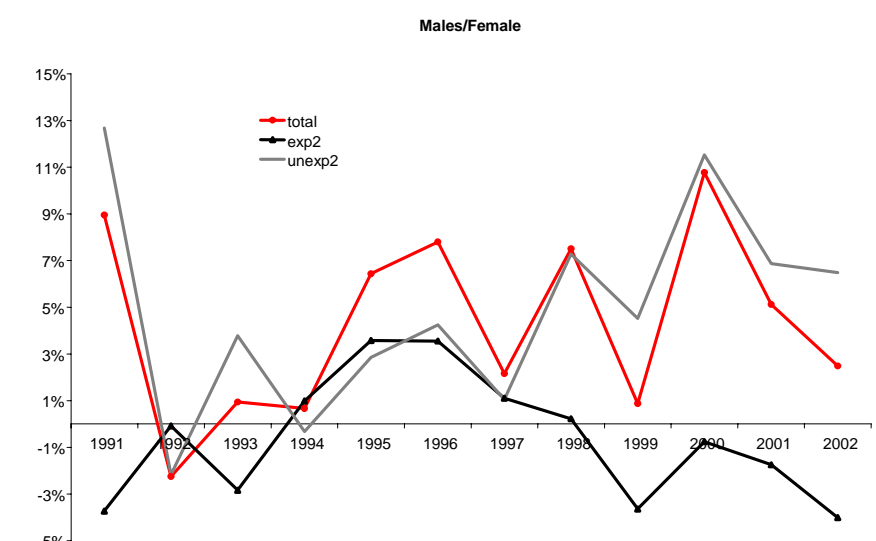

years
Figure 7: Estimated participation gap, non-carers/cares, females $\beta^{*}=\beta^{N C}$

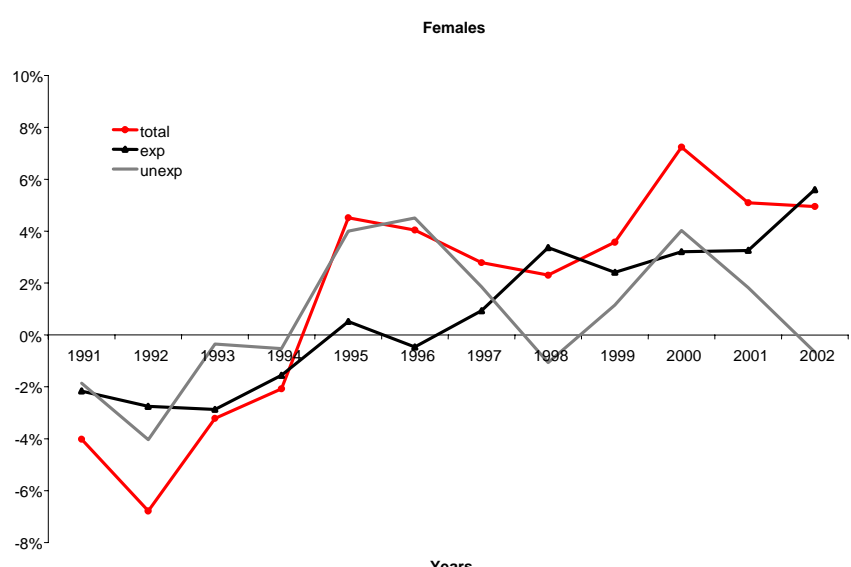

Figure 9: Estimated participation gap, male/female $\beta^{*}=\beta^{M}$

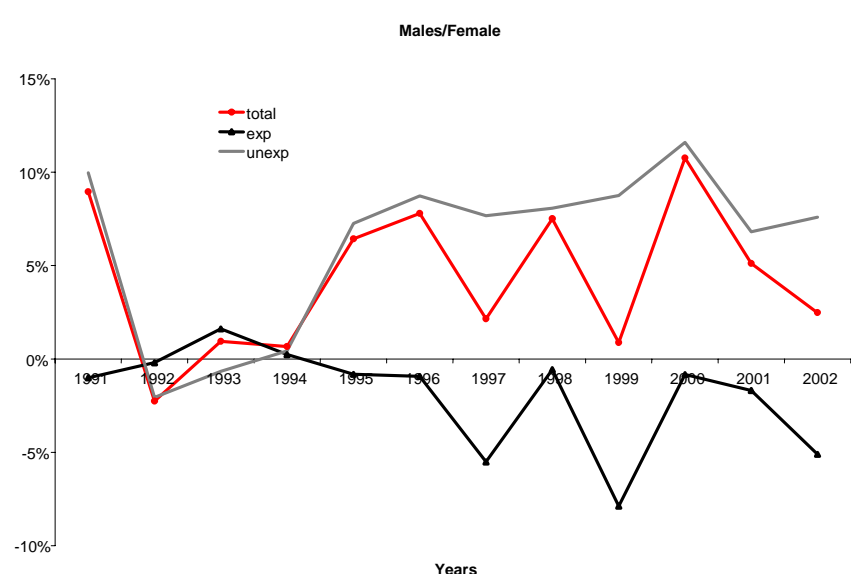


Table 8: Decomposition of participation gap, non carers/carers, overall

\begin{tabular}{|c|c|c|c|c|c|c|}
\hline $\begin{array}{l}\text { All } \\
\text { Year }\end{array}$ & 1991 & 1992 & 1993 & 1994 & 1995 & 1996 \\
\hline$\overline{\mathrm{Par}}^{\mathrm{NC}}-\overline{\mathrm{Par}}^{\mathrm{C}}$ & $-0.0279 *$ & $-0.0338 *$ & $0.0166 *$ & $0.0276 *$ & $0.0691 * *$ & $0.0519 * *$ \\
\hline$\hat{\beta}^{N C}\left(\bar{X}^{N C}-\bar{X}^{C}\right)$ & $-0.0079 *$ & $-0.0131^{*}$ & $-0.0057 *$ & $0.0063 *$ & $0.0128 *$ & $0.0086^{*}$ \\
\hline $\bar{X}^{C}\left(\hat{\beta}^{N C}-\hat{\beta}^{C}\right)$ & $-0.0200 *$ & $-0.0208^{*}$ & $0.0223^{*}$ & $0.0213^{*}$ & $0.0563 * *$ & $0.0433^{* *}$ \\
\hline$\hat{\beta}^{C}\left(\bar{X}^{N C}-\bar{X}^{C}\right)$ & $-0.0086^{*}$ & $-0.0048^{*}$ & $0.0012^{*}$ & $0.0154^{*}$ & $-0.0016^{* *}$ & $0.0106^{*}$ \\
\hline \multirow[t]{2}{*}{$\bar{X}^{N C}\left(\hat{\beta}^{N C}-\hat{\beta}^{C}\right)$} & $-0.0193^{*}$ & $-0.0290 *$ & $0.0154 *$ & $0.0122 *$ & $0.0707 * *$ & $0.0413^{*}$ \\
\hline & 1997 & 1998 & 1999 & 2000 & 2001 & 2002 \\
\hline$\overline{P a r}^{N C}-\overline{P a r}^{C}$ & $0.0715 * *$ & $0.0422 *$ & $0.0847^{* *}$ & $0.0744 * *$ & $0.0741 * *$ & $0.0727 * *$ \\
\hline$\hat{\beta}^{N C}\left(\bar{X}^{N C}-\bar{X}^{C}\right)$ & $0.0305^{* *}$ & $0.0475 * *$ & $0.0476^{* *}$ & $0.0499 * *$ & $0.0520 * *$ & $0.0649 * *$ \\
\hline $\bar{X}^{C}\left(\hat{\beta}^{N C}-\hat{\beta}^{C}\right)$ & $0.0409 *$ & $-0.0052 *$ & 0.0370 & 0.0246 & 0.0222 & 0.0078 \\
\hline$\hat{\beta}^{C}\left(\bar{X}^{N C}-\bar{X}^{C}\right)$ & $0.0088^{*}$ & $0.0425^{* *}$ & $0.0546^{* *}$ & $0.0445 * *$ & $0.0437 * *$ & $0.0542 * *$ \\
\hline $\bar{X}^{N C}\left(\hat{\beta}^{N C}-\hat{\beta}^{C}\right)$ & $0.0626 * *$ & -0.0003 & 0.0301 & 0.0300 & 0.0304 & 0.0186 \\
\hline
\end{tabular}

Note: Significance is based on $95 \%$ and $90 \%$ bootstrap confidence intervals for 500 replications, $* *$ and *indicate significance at $95 \%$ and $90 \%$ level. If not otherwise stated differences are significant for all three approaches (normal, percentile, and bias corrected).

Table 9: Decomposition of participation gap, non carers/carers, males

\begin{tabular}{lllllll}
\hline Males & & & & & \\
Year & 1991 & 1992 & 1993 & 1994 & 1995 & 1996 \\
\hline$\overline{P a r}^{N C}-\overline{P a r}^{C}$ & $\mathbf{0 . 0 0 2 7}$ & $\mathbf{0 . 0 9 3 1}$ & $\mathbf{0 . 0 7 6 9}$ & $\mathbf{0 . 0 8 8 6}$ & $\mathbf{0 . 0 8 8 0 * *}$ & $\mathbf{0 . 0 6 0 1}(\mathbf{P})^{* *}$ \\
$\hat{\beta}^{N C}\left(\bar{X}^{N C}-\bar{X}^{C}\right)$ & 0.0175 & 0.0222 & 0.0092 & 0.0269 & 0.0238 & 0.0283 \\
$\bar{X}^{C}\left(\hat{\beta}^{N C}-\hat{\beta}^{C}\right)$ & -0.0148 & 0.0709 & 0.0678 & 0.0617 & $0.0642 * *$ & 0.0318 \\
$\hat{\beta}^{C}\left(\bar{X}^{N C}-\bar{X}^{C}\right)$ & -0.0047 & 0.0084 & 0.0138 & 0.0568 & 0.0508 & 0.0521 \\
$\bar{X}^{N C}\left(\hat{\beta}^{N C}-\hat{\beta}^{C}\right)$ & 0.0074 & 0.0847 & 0.0631 & 0.0317 & $(\mathrm{P})^{* *}$ & 0.0080 \\
\hline$\overline{P a r}^{N C}-\overline{P a r}^{C}$ & 1997 & 1998 & 1999 & 2000 & 2001 & 2002 \\
$\hat{\beta}^{N C}\left(\bar{X}^{N C}-\bar{X}^{C}\right)$ & $0.0685^{* *}$ & $0.0608 * *$ & $0.0699 * *$ & $0.0453(\mathrm{P})^{* *}$ & $0.0650^{* *}$ & $0.0702^{* *}$ \\
$\bar{X}^{C}\left(\hat{\beta}^{N C}-\hat{\beta}^{C}\right)$ & $0.0552^{*}$ & -0.0050 & $0.0830^{* *}$ & 0.0199 & 0.0320 & 0.0293 \\
$\hat{\beta}^{C}\left(\bar{X}^{N C}-\bar{X}^{C}\right)$ & $0.0773 * *$ & $0.0609 * *$ & $0.0938^{* *}$ & 0.0533 & $0.0665 * *$ & $0.0847 * *$ \\
$\bar{X}^{N C}\left(\hat{\beta}^{N C}-\hat{\beta}^{C}\right)$ & 0.0464 & $-0.0051(\mathrm{P})^{* *}$ & $0.0590^{* *}$ & 0.0119 & 0.0304 & 0.0149 \\
\hline
\end{tabular}

Note: Significance is based on $95 \%$ and $90 \%$ bootstrap confidence intervals for 500 replications, $* *$ and *indicate significance at $95 \%$ and $90 \%$ level. If not otherwise stated differences are significant for all three approaches (normal, percentile, and bias corrected). 
Table 10: Decomposition of participation gap, non carers/carers, females

\begin{tabular}{lllllll}
\hline Females & & & & & \\
Year & 1991 & 1992 & 1993 & 1994 & 1995 & 1996 \\
\hline$\overline{P a r}^{N C}-\overline{P a r}^{C}$ & $\mathbf{- 0 . 0 4 0 2}$ & $\mathbf{- 0 . 0 6 7 9}$ & $\mathbf{- 0 . 0 3 2 2}$ & $\mathbf{- 0 . 0 2 0 8}$ & $\mathbf{0 . 0 4 5 2}$ & $\mathbf{0 . 0 4 0 4}$ \\
$\hat{\beta}^{N C}\left(\bar{X}^{N C}-\bar{X}^{C}\right)$ & -0.0216 & -0.0275 & -0.0287 & -0.0155 & 0.0052 & -0.0046 \\
$\bar{X}^{C}\left(\hat{\beta}^{N C}-\hat{\beta}^{C}\right)$ & -0.0186 & -0.0403 & -0.0035 & -0.0053 & 0.0400 & 0.0451 \\
$\hat{\beta}^{C}\left(\bar{X}^{N C}-\bar{X}^{C}\right)$ & -0.0253 & -0.0284 & -0.0295 & -0.0311 & -0.0367 & -0.0255 \\
$\bar{X}^{N C}\left(\hat{\beta}^{N C}-\hat{\beta}^{C}\right)$ & -0.0148 & -0.0394 & -0.0027 & 0.0103 & $0.0819^{* *}$ & 0.0659 \\
\hline & 1997 & 1998 & 1999 & 2000 & 2001 & 2002 \\
\hline$\overline{P a r}^{N C}-\overline{P a r}^{C}$ & $\mathbf{0 . 0 2 7 9}$ & $\mathbf{0 . 0 2 3 0}$ & $\mathbf{0 . 0 3 5 7}$ & $\mathbf{0 . 0 7 2 4} * *$ & $\mathbf{0 . 0 5 0 9}$ & $\mathbf{0 . 0 4 9 5}$ \\
$\hat{\beta}^{N C}\left(\bar{X}^{N C}-\bar{X}^{C}\right)$ & $0.0093 *$ & $0.0337 * *$ & $0.0241 * *$ & $0.0321 * *$ & $0.0326 * *$ & $0.0560 * *$ \\
$\bar{X}^{C}\left(\hat{\beta}^{N C}-\hat{\beta}^{C}\right)$ & 0.0186 & -0.0106 & 0.0116 & 0.0403 & 0.0183 & -0.0065 \\
$\hat{\beta}^{C}\left(\bar{X}^{N C}-\bar{X}^{C}\right)$ & -0.0317 & 0.0035 & 0.0282 & 0.0070 & 0.0185 & 0.0268 \\
$\bar{X}^{N C}\left(\hat{\beta}^{N C}-\hat{\beta}^{C}\right)$ & 0.0596 & 0.0196 & 0.0075 & 0.0654 & 0.0324 & 0.0227 \\
\hline
\end{tabular}

Note: Significance is based on $95 \%$ and $90 \%$ bootstrap confidence intervals for 500 replications, ** and *indicate significance at $95 \%$ and $90 \%$ level. If not otherwise stated differences are significant for all three approaches (normal, percentile, and bias corrected).

Table 11: Decomposition of participation gap male/female

\begin{tabular}{lllllll}
\hline Male/Female & & & & & \\
Year & 1991 & 1992 & 1993 & 1994 & 1995 & 1996 \\
\hline$\overline{P a r}^{N C}-\overline{P a r}$ & $\mathbf{0 . 0 8 9 5}$ & $\mathbf{- 0 . 0 2 2 6}$ & $\mathbf{0 . 0 0 9 5}$ & $\mathbf{0 . 0 0 6 6}$ & $\mathbf{0 . 0 6 4 3}$ & $\mathbf{0 . 0 7 8 0}$ \\
$\Delta$ non-carers & -0.0429 & -0.1609 & -0.1091 & -0.1093 & -0.0428 & -0.0196 \\
$\hat{\beta}^{C M}\left(\bar{X}^{C M}-\bar{X}^{C F}\right)$ & -0.0102 & -0.0020 & 0.0160 & 0.0023 & -0.0082 & -0.0094 \\
$\bar{X}^{C F}\left(\hat{\beta}^{C M}-\hat{\beta}^{C F}\right)$ & 0.0997 & -0.0205 & -0.0066 & 0.0044 & 0.0726 & 0.0873 \\
$\hat{\beta}^{C F}\left(\bar{X}^{C M}-\bar{X}^{C F}\right)$ & -0.0373 & -0.0009 & -0.0284 & 0.0099 & 0.0358 & 0.0355 \\
$\bar{X}^{C M}\left(\hat{\beta}^{C M}-\hat{\beta}^{C F}\right)$ & 0.1268 & -0.0217 & 0.0378 & -0.0033 & 0.0285 & 0.0424 \\
\hline & 1997 & 1998 & 1999 & 2000 & 2001 & 2002 \\
\hline$\overline{P a r}^{N C}-\overline{P a r}^{C}$ & $\mathbf{0 . 0 2 1 5}$ & $\mathbf{0 . 0 7 5 0}$ & $\mathbf{0 . 0 0 8 7}$ & $\mathbf{0 . 1 0 7 7 * *}$ & $\mathbf{0 . 0 5 1 2}$ & $\mathbf{0 . 0 2 4 8}$ \\
$\Delta$ non-Carers & -0.0958 & -0.0328 & -0.1171 & 0.0072 & -0.0461 & -0.0290 \\
$\hat{\beta}^{C M}\left(\bar{X}^{C M}-\bar{X}^{C F}\right)$ & -0.0551 & -0.0058 & -0.0788 & -0.0084 & -0.0169 & -0.0511 \\
$\bar{X}^{C F}\left(\hat{\beta}^{C M}-\hat{\beta}^{C F}\right)$ & 0.0767 & 0.0808 & 0.0876 & $0.1160 * *$ & 0.0681 & 0.0759 \\
$\hat{\beta}^{C F}\left(\bar{X}^{C M}-\bar{X}^{C F}\right)$ & 0.0110 & 0.0022 & -0.0364 & -0.0076 & -0.0175 & -0.0401 \\
$\bar{X}^{C M}\left(\hat{\beta}^{C M}-\hat{\beta}^{C F}\right)$ & 0.0105 & 0.0728 & 0.0452 & $0.1153 * *$ & 0.0687 & 0.0649 \\
\hline
\end{tabular}

Note: Significance is based on $95 \%$ and $90 \%$ bootstrap confidence intervals for 500 replications, ** and $*$ indicate significance at $95 \%$ and $90 \%$ level. If not otherwise stated differences are significant for all three approaches (normal, percentile, and bias corrected). 
Table 12: Decomposition of participation gap, BHPS 1991-2002

\begin{tabular}{lllll}
\hline & All & Male & Female & Male/Female \\
\hline $\ln \bar{W}^{C M}-\ln \bar{W}^{C F}$ & $0.3304^{* *}$ & $0.0397^{* *}$ & $0.0179 * *$ & $0.0891^{* *}$ \\
$\hat{\beta}^{N C}\left(\bar{X}^{N C}-\bar{X}^{C}\right)$ & $0.0187^{* *}$ & $0.0283^{* *}$ & 0.0039 & $-0.02169^{* *}$ \\
$\bar{X}^{C}\left(\hat{\beta}^{N C}-\hat{\beta}^{C}\right)$ & $0.0143^{* *}$ & $0.0114^{*}$ & 0.0139 & $0.1108^{* *}$ \\
$\hat{\beta}^{C}\left(\bar{X}^{N C}-\bar{X}^{C}\right)$ & $0.0221^{* *}$ & $0.0325^{* *}$ & 0.0080 & -0.0109 \\
$\bar{X}^{N C}\left(\hat{\beta}^{N C}-\hat{\beta}^{C}\right)$ & 0.0109 & $0.0072^{*}$ & 0.0150 & $0.1000^{* *}$ \\
\hline
\end{tabular}

Note: Significance is based on $95 \%$ and $90 \%$ bootstrap confidence intervals for 500 replications, $* *$ and *indicate significance at $95 \%$ and $90 \%$ level. If not otherwise stated differences are significant for all three approaches (normal, percentile, and bias corrected). 
Table 13: Fixed effects log hourly wage regression, BHPS 1991-2002

\begin{tabular}{|c|c|c|c|c|c|c|c|c|c|c|c|c|}
\hline & \multicolumn{2}{|l|}{ Model I } & \multicolumn{2}{|l|}{ Model II } & \multicolumn{2}{|c|}{ Model III } & \multicolumn{2}{|l|}{ Model IV } & \multicolumn{2}{|l|}{ Model V } & \multicolumn{2}{|c|}{ Model VI } \\
\hline & Coeff & t-value & Coeff & t-value & Coeff & t-value & Coeff & t-value & Coeff & t-value & Coeff & t-value \\
\hline Constant & 2.6246 & $62.92 * *$ & 2.6270 & $62.99 * *$ & 2.5120 & $15.07 * *$ & 2.4991 & $14.47 * *$ & 2.1193 & $2.90 * *$ & 2.0384 & $2.68^{* *}$ \\
\hline Age Sq & -0.0008 & $-29.85 * *$ & -0.0008 & $-29.82 * *$ & -0.0006 & $-5.61 * *$ & -0.0006 & $-5.49 * *$ & -0.0002 & -0.73 & -0.0002 & -0.61 \\
\hline Disabled & -0.0310 & $-3.45^{* *}$ & -0.0304 & $-3.38 * *$ & 0.0115 & 0.49 & 0.0015 & 0.06 & -0.0413 & -0.70 & -0.0469 & -0.78 \\
\hline Part-time & 0.0291 & $3.79 * *$ & 0.0289 & $3.77 * *$ & 0.0779 & $3.13^{* *}$ & 0.0771 & $3.06^{* *}$ & 0.0241 & 0.38 & 0.0262 & 0.41 \\
\hline Public & 0.0203 & $2.83 * *$ & 0.0209 & $2.91^{* *}$ & 0.0205 & 0.85 & 0.0242 & 0.99 & 0.1014 & $1.86^{*}$ & 0.1039 & $1.89 *$ \\
\hline Married & 0.0285 & $3.93 * *$ & 0.0284 & $3.91^{* *}$ & 0.0153 & 0.54 & 0.0215 & 0.74 & 0.0958 & 1.15 & 0.0843 & 0.99 \\
\hline Professional & 0.1512 & $10.80^{* *}$ & 0.1513 & $10.80 * *$ & 0.0857 & 1.60 & 0.0814 & 1.51 & 0.1441 & 1.03 & 0.1452 & 1.03 \\
\hline Managerial & 0.1596 & $16.87 * *$ & 0.1591 & $16.82 * *$ & 0.1587 & $4.92 * *$ & 0.1592 & $4.91^{* *}$ & 0.2163 & $2.73^{* *}$ & 0.2177 & $2.74 * *$ \\
\hline Skilled non manual & 0.0489 & $5.29 * *$ & 0.0483 & $5.23^{* *}$ & 0.0298 & 0.97 & 0.0280 & 0.91 & 0.0600 & 0.89 & 0.0605 & 0.89 \\
\hline Skilled manual & 0.0428 & $4.97 * *$ & 0.0425 & $4.93 * *$ & 0.0191 & 0.66 & 0.0179 & 0.62 & -0.1123 & $-1.63^{*}$ & -0.1131 & $-1.63^{*}$ \\
\hline Higher degree & 0.3319 & $8.10^{* *}$ & 0.3304 & $8.07 * *$ & 0.0847 & 0.60 & 0.1120 & 0.78 & & & & \\
\hline Degree & 0.2092 & $6.81^{* *}$ & 0.2092 & $6.81 * *$ & -0.0765 & -0.78 & -0.0538 & -0.53 & 0.4350 & 1.54 & 0.4274 & 1.49 \\
\hline A-level & 0.0291 & 1.03 & 0.0296 & 1.05 & 0.0087 & 0.10 & 0.0317 & 0.35 & 0.4778 & $2.26^{* *}$ & 0.4560 & $2.13^{* *}$ \\
\hline O-level and below & -0.0185 & -0.68 & -0.0182 & -0.67 & 0.0017 & 0.02 & 0.0182 & 0.22 & 0.3269 & $2.06^{* *}$ & 0.3266 & $2.05^{* *}$ \\
\hline Tenure Sq & 0.0001 & $2.74 * *$ & 0.0001 & $2.75^{* *}$ & 0.0000 & 0.60 & 0.0001 & 0.87 & -0.0001 & -0.82 & -0.0001 & -0.74 \\
\hline Small & -0.0828 & $-10.83^{* *}$ & -0.0826 & $-10.80 * *$ & -0.0397 & -1.53 & -0.0423 & -1.61 & -0.0273 & -0.42 & -0.0276 & -0.42 \\
\hline Medium & -0.0203 & $-2.89 * *$ & -0.0200 & $-2.86 * *$ & -0.0515 & $-2.18^{* *}$ & -0.0537 & $-2.23 * *$ & 0.0119 & 0.21 & 0.0144 & 0.25 \\
\hline Carer & & & -0.0266 & $-3.98 * *$ & & & & & & & & \\
\hline Cared 20+ & & & & & & & -0.0208 & -0.87 & & & & \\
\hline Cared for Parent & & & & & & & 0.0091 & 0.35 & & & 0.0142 & 0.17 \\
\hline Cared for Spouse & & & & & & & -0.0549 & -1.14 & & & 0.1342 & 0.86 \\
\hline Cared for Children & & & & & & & -0.0633 & -1.00 & & & -0.0638 & -0.44 \\
\hline Cared for Other & & & & & & & 0.0113 & 0.45 & & & 0.0191 & 0.23 \\
\hline Care Duration & & & & & & & & & -0.0245 & $-2.08 * *$ & -0.0255 & $-2.13^{* *}$ \\
\hline Time Dummies & Yes & & Yes & & Yes & & Yes & & Yes & & Yes & \\
\hline VN term significant & Yes & & Yes & & Yes & & Yes & & No & & No & \\
\hline $\mathrm{N}$ & 24061 & & 24059 & & 3212 & & 3126 & & 786 & & 786 & \\
\hline R2 within & 0.2489 & & 0.2494 & & 0.1266 & & 0.1306 & & 0.1273 & & 0.1301 & \\
\hline R2 overall & 0.0056 & & 0.0056 & & 0.0000 & & 0 & & 0.0511 & & 0.0641 & \\
\hline Breusch/Pagan Pr $>$ Chisq & 0.0000 & & 0.0000 & & 0.0000 & & 0.0000 & & 0.0000 & & 0.0000 & \\
\hline Hausman Pr $>$ Chisq & 0.0000 & & 0.0000 & & 0.0000 & & 0.0000 & & 0.0000 & & 0.0000 & \\
\hline
\end{tabular}

Note: Model I: All; Model II All; Model III: Carers; Model IV: Carers, additional regressors; Model V: Carers, addition
additional regressors, 1991 and 2002 excluded. **indicates 95\% significance level, * indicates 90\% significance level. 
Figure 10: Estimated log hourly wage gap, non-carers/carers, overall $\beta^{*}=\beta^{C}$

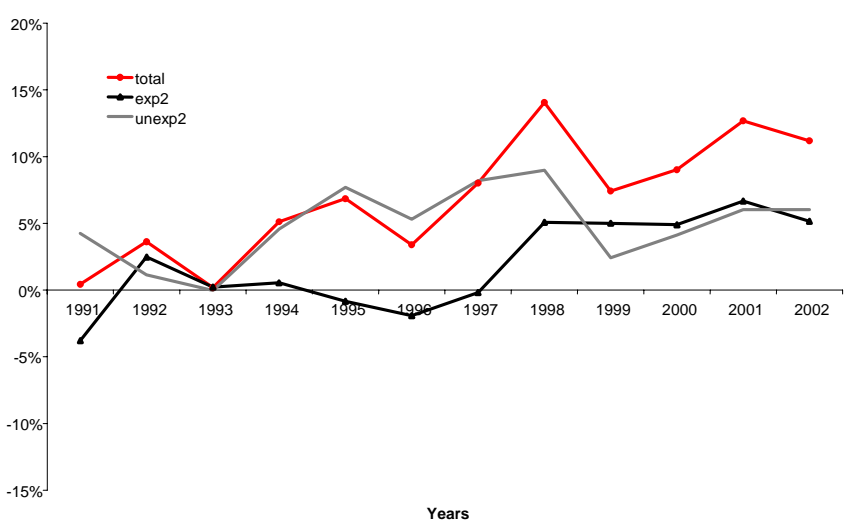

Figure 12: Estimated log hourly wage gap, non-carers/carers, females $\beta^{*}=\beta^{C}$

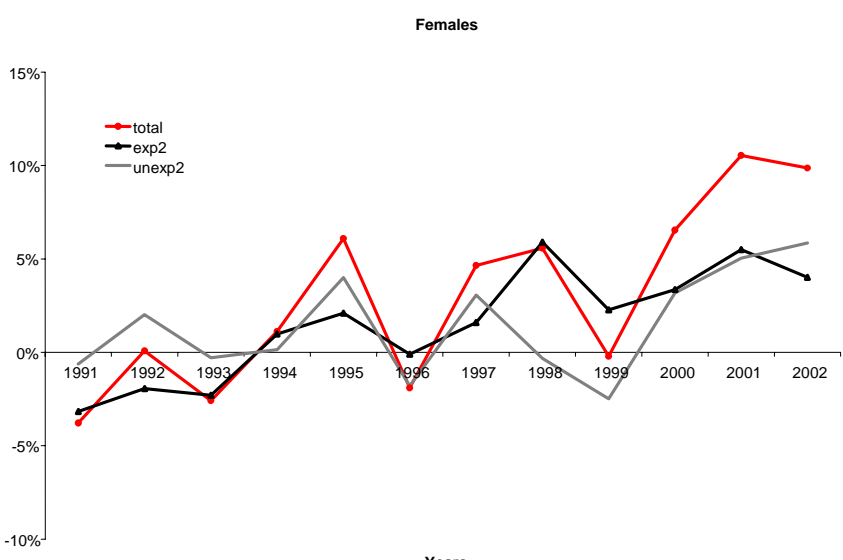

Years
Figure 11: Estimated $\log$ hourly wage gap, non-carers/carers, overall $\beta^{*}=\beta^{N C}$

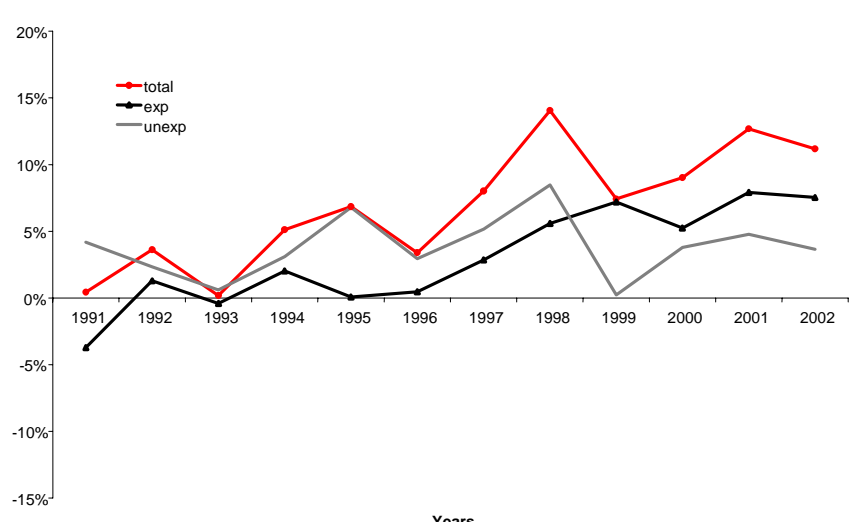

Figure 13: Estimated log hourly wage gap, non-carers/carers, females $\beta^{*}=\beta^{N C}$

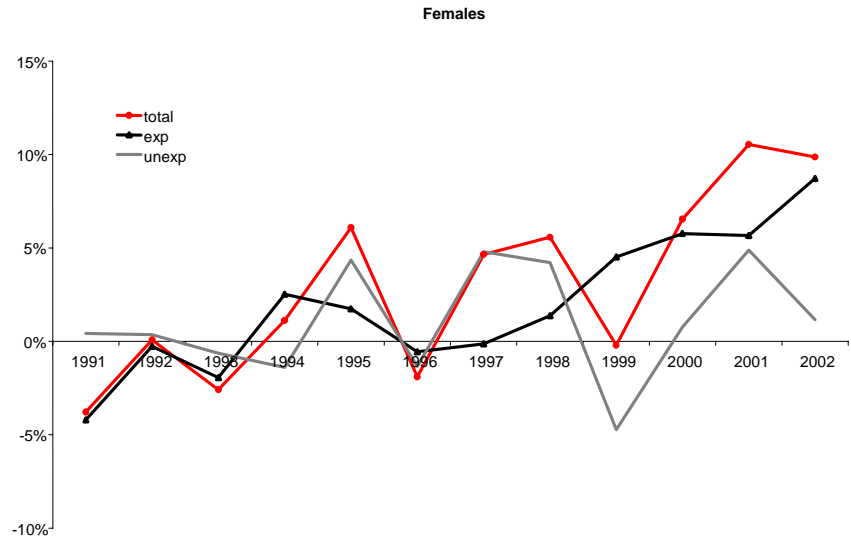

Years 
Figure 14: Estimated log hourly wage gap, non-carers/carers, males $\beta^{*}=\beta^{C}$

Males

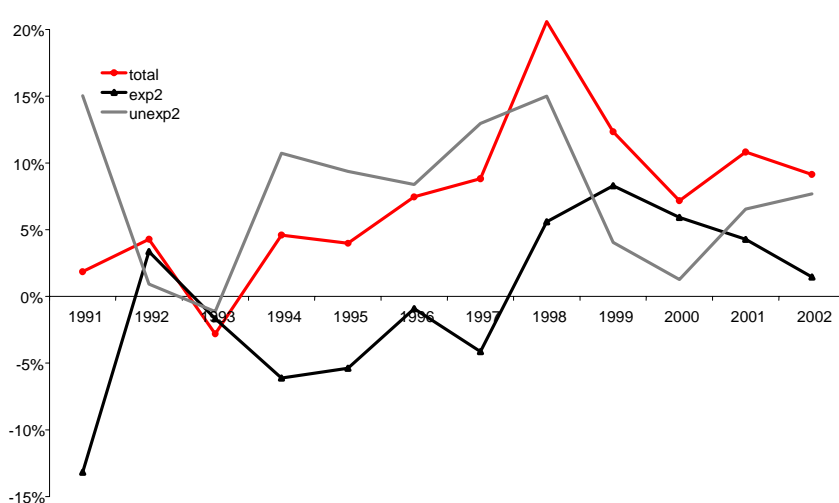

Years

Figure 16: Estimated log hourly wage gap, male/female $\beta^{*}=\beta^{F}$ Males/Female

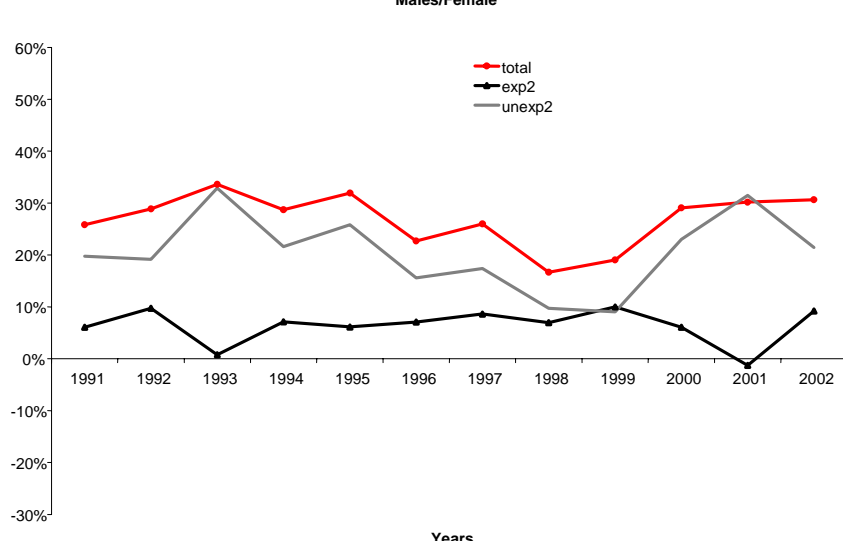

Figure 15: Estimated log hourly wage gap, non-carers/carers, males $\beta^{*}=\beta^{N C}$

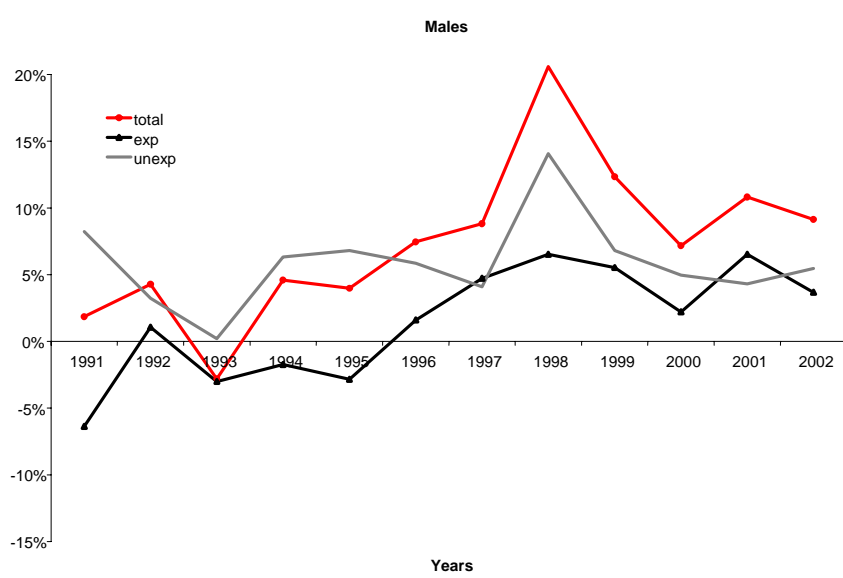

Figure 17: Estimated log hourly wage gap, male/female $\beta^{*}=\beta^{M}$

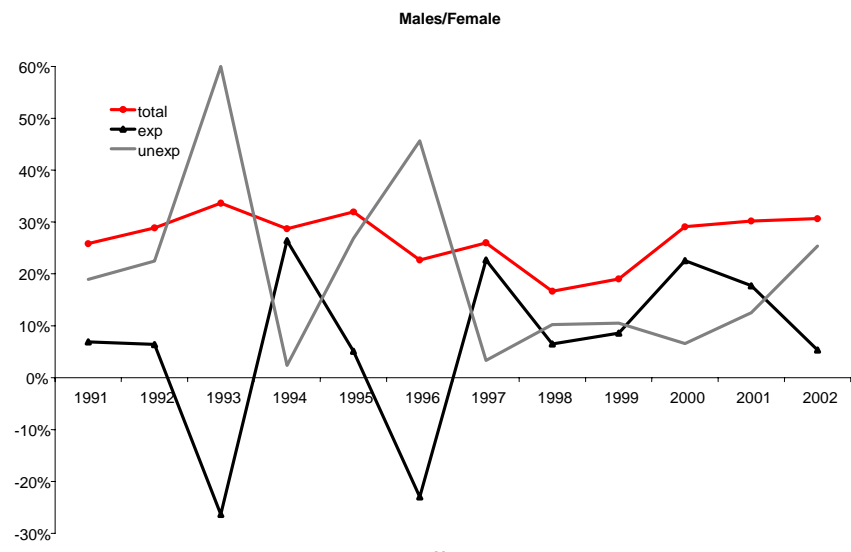


Table 14: Decomposition of log hourly wage gap, non-carers/carers, overall BHPS 1991-2002

\begin{tabular}{lllllll}
\hline All & & & & & \\
Year & 1991 & 1992 & 1993 & 1994 & 1995 & 1996 \\
\hline $\ln \bar{W}^{C M}-\ln \bar{W}^{C F}$ & $0.0044^{* *}$ & $0.0361^{* *}$ & $0.0019^{* *}$ & $0.0512^{* *}$ & $0.0685^{* *}$ & $0.0339^{* *}$ \\
$\hat{\beta}^{N C}\left(\bar{X}^{N C}-\bar{X}^{C}\right)$ & $-0.0373^{* *}$ & $0.0128^{* *}$ & $-0.0041^{* *}$ & $0.0202^{* *}$ & $0.0006^{* *}$ & $0.0045^{* *}$ \\
$\bar{X}^{C}\left(\hat{\beta}^{N C}-\hat{\beta}^{C}\right)$ & $0.0417^{* *}$ & $0.0234^{* *}$ & $0.0060^{* *}$ & $0.0310^{* *}$ & $0.0679 * *$ & $0.0294^{* *}$ \\
$\hat{\beta}^{C}\left(\bar{X}^{N C}-\bar{X}^{C}\right)$ & $-0.0381^{* *}$ & $0.0247^{* *}$ & $0.0022^{* *}$ & $0.0054^{* *}$ & $-0.0085^{* *}$ & $-0.0193^{* *}$ \\
$\bar{X}^{N C}\left(\hat{\beta}^{N C}-\hat{\beta}^{C}\right)$ & $0.0424^{* *}$ & $0.0114^{* *}$ & $(\mathrm{BC})^{* *}$ & $0.0458^{* *}$ & $0.0769 * *$ & $0.0532^{* *}$ \\
\hline & 1997 & 1998 & 1999 & 2000 & 2001 & 2002 \\
\hline $\ln \bar{W}^{C M}-\ln \bar{W}^{C F}$ & $0.0801^{* *}$ & $0.1405^{* *}$ & $0.0741^{* *}$ & $0.0902 * *$ & $0.1268^{* *}$ & $0.1118^{* *}$ \\
$\hat{\beta}^{N C}\left(\bar{X}^{N C}-\bar{X}^{C}\right)$ & $0.0285^{* *}$ & $0.0558^{* *}$ & $0.0720^{* *}$ & $0.0524 * *$ & $0.0790^{* *}$ & $0.0753^{* *}$ \\
$\bar{X}^{C}\left(\hat{\beta}^{N C}-\hat{\beta}^{C}\right)$ & $0.0517^{* *}$ & $0.0847^{* *}$ & $0.0022^{* *}$ & $0.0378^{* *}$ & $0.0478^{* *}$ & $0.0365^{* *}$ \\
$\hat{\beta}^{C}\left(\bar{X}^{N C}-\bar{X}^{C}\right)$ & $-0.0019^{* *}$ & $0.0507^{* *}$ & $0.0499^{* *}$ & $0.0489^{* *}$ & $0.0666^{* *}$ & $0.0515^{* *}$ \\
$\bar{X}^{N C}\left(\hat{\beta}^{N C}-\hat{\beta}^{C}\right)$ & $0.0821^{* *}$ & $0.0898^{* *}$ & $0.0242^{* *}$ & $0.0413^{* *}$ & $0.0602^{* *}$ & $0.0603^{* *}$ \\
\hline
\end{tabular}

Note: Significance is based on $95 \%$ and $90 \%$ bootstrap confidence intervals for 500 replications, ** and $*$ indicate significance at $95 \%$ and $90 \%$ level. If not otherwise stated differences are significant for all three approaches (normal, percentile, and bias corrected).

Table 15: Decomposition of log hourly wage gap, non-carers/carers, males BHPS 1991-2002

\begin{tabular}{lllllll}
\hline Males & & & & & \\
Year & 1991 & 1992 & 1993 & 1994 & 1995 & 1996 \\
\hline $\ln \bar{W}^{C M}-\ln \bar{W}^{C F}$ & $0.0185^{* *}$ & $0.0428^{* *}$ & $-0.0281^{* *}$ & $0.0460^{* *}$ & $0.0398^{* *}$ & $0.0746^{* *}$ \\
$\hat{\beta}^{N C}\left(\bar{X}^{N C}-\bar{X}^{C}\right)$ & $-0.0638^{* *}$ & $0.0106^{* *}$ & $-0.0302^{* *}$ & $-0.0173^{* *}$ & $-0.0283^{* *}$ & $0.0159^{* *}$ \\
$\bar{X}^{C}\left(\hat{\beta}^{N C}-\hat{\beta}^{C}\right)$ & $0.0822^{* *}$ & $0.0322^{* *}$ & $0.0021^{*}$ & $0.0633^{* *}$ & $0.0681^{* *}$ & $0.0586^{* *}$ \\
$\hat{\beta}^{C}\left(\bar{X}^{N C}-\bar{X}^{C}\right)$ & $-0.1318^{* *}$ & $0.0336^{* *}$ & $-0.0167^{* *}$ & $-0.0613^{* *}$ & $-0.0538^{* *}$ & $-0.0093^{* *}$ \\
$\bar{X}^{N C}\left(\hat{\beta}^{N C}-\hat{\beta}^{C}\right)$ & $0.1503^{* *}$ & $0.0092^{*}$ & $-0.0114^{* *}$ & $0.1073^{* *}$ & $0.0936^{* *}$ & $0.0839^{* *}$ \\
\hline & 1997 & 1998 & 1999 & 2000 & 2001 & 2002 \\
\hline $\ln \bar{W}^{C M}-\ln \bar{W}^{C F}$ & $0.0881^{* *}$ & $0.2060^{* *}$ & $0.1234^{* *}$ & $0.0717^{* *}$ & $0.1082^{* *}$ & $0.0914^{* *}$ \\
$\hat{\beta}^{N C}\left(\bar{X}^{N C}-\bar{X}^{C}\right)$ & $0.0472^{* *}$ & $0.0654^{* *}$ & $0.0553^{* *}$ & $0.0221^{* *}$ & $0.0652^{* *}$ & $0.0367^{* *}$ \\
$\bar{X}^{C}\left(\hat{\beta}^{N C}-\hat{\beta}^{C}\right)$ & $0.0409^{* *}$ & $0.1406^{* *}$ & $0.0681^{* *}$ & $0.0496^{* *}$ & $0.0430^{* *}$ & $0.0547^{* *}$ \\
$\hat{\beta}^{C}\left(\bar{X}^{N C}-\bar{X}^{C}\right)$ & $-0.0414^{* *}$ & $0.0560^{* *}$ & $0.0829^{* *}$ & $0.0591^{* *}$ & $0.0427^{* *}$ & $0.0146^{* *}$ \\
$\bar{X}^{N C}\left(\hat{\beta}^{N C}-\hat{\beta}^{C}\right)$ & $0.1295^{* *}$ & $0.1501^{* *}$ & $0.0405^{* *}$ & $0.0126^{* *}$ & $0.0655^{* *}$ & $0.0768^{* *}$ \\
\hline
\end{tabular}

Note: Significance is based on $95 \%$ and $90 \%$ bootstrap confidence intervals for 500 replications, ** and $*$ indicate significance at $95 \%$ and $90 \%$ level. If not otherwise stated differences are significant for all three approaches (normal, percentile, and bias corrected). 
Table 16: Decomposition of log hourly wage gap, non-carers/carers, females BHPS 1991-2002

\begin{tabular}{lllllll}
\hline Females & & & & & \\
Year & 1991 & 1992 & 1993 & 1994 & 1995 & 1996 \\
\hline $\ln \bar{W}^{C M}-\ln \bar{W}^{C F}$ & $-0.0379^{* *}$ & $0.0008^{* *}$ & $-0.0259^{* *}$ & $0.0112^{* *}$ & $0.0608^{* *}$ & $-0.0191^{* *}$ \\
$\hat{\beta}^{N C}\left(\bar{X}^{N C}-\bar{X}^{C}\right)$ & $-0.0421^{* *}$ & -0.0027 & $-0.0194^{* *}$ & $0.0251^{* *}$ & $0.0174^{* *}$ & $-0.0056^{* *}$ \\
$\bar{X}^{C}\left(\hat{\beta}^{N C}-\hat{\beta}^{C}\right)$ & $0.0041^{* *}$ & $0.0035^{* *}$ & $-0.0065^{* *}$ & $-0.0140^{* *}$ & $0.0435^{* *}$ & $-0.0135^{* *}$ \\
$\hat{\beta}^{C}\left(\bar{X}^{N C}-\bar{X}^{C}\right)$ & $-0.0317^{* *}$ & $-0.0194^{* *}$ & $-0.0230^{* *}$ & $0.0098^{* *}$ & $0.0209^{* *}$ & $-0.0010^{* *}$ \\
$\bar{X}^{N C}\left(\hat{\beta}^{N C}-\hat{\beta}^{C}\right)$ & $-0.0063^{* *}$ & $0.0202^{* *}$ & -0.0029 & 0.0014 & $0.0399^{* *}$ & $-0.0181^{* *}$ \\
\hline & 1997 & 1998 & 1999 & 2000 & 2001 & 2002 \\
\hline $\ln \bar{W}^{C M}-\ln \bar{W}^{C F}$ & $0.0465^{* *}$ & $0.0557^{* *}$ & $-0.0022^{* *}$ & $0.0654^{* *}$ & $0.1054^{* *}$ & $0.0986^{* *}$ \\
$\hat{\beta}^{N C}\left(\bar{X}^{N C}-\bar{X}^{C}\right)$ & -0.0014 & $0.0137^{* *}$ & $0.0451^{* *}$ & $0.0577^{* *}$ & $0.0566^{* *}$ & $0.0871^{* *}$ \\
$\bar{X}^{C}\left(\hat{\beta}^{N C}-\hat{\beta}^{C}\right)$ & $0.0479^{* *}$ & $0.0421^{* *}$ & $-0.0474^{* *}$ & $0.0077^{* *}$ & $0.0488^{* *}$ & $0.0115^{* *}$ \\
$\hat{\beta}^{C}\left(\bar{X}^{N C}-\bar{X}^{C}\right)$ & $0.0159^{* *}$ & $0.0591^{* *}$ & $0.0227^{* *}$ & $0.0336^{* *}$ & $0.0551^{* *}$ & $0.0401^{* *}$ \\
$\bar{X}^{N C}\left(\hat{\beta}^{N C}-\hat{\beta}^{C}\right)$ & $0.0306^{* *}$ & $-0.0033^{* *}$ & $-0.0250^{* *}$ & $0.0318^{* *}$ & $0.0503^{* *}$ & $0.0585^{* *}$ \\
\hline
\end{tabular}

Note: Significance is based on $95 \%$ and $90 \%$ bootstrap confidence intervals for 500 replications, ** and *indicate significance at $95 \%$ and $90 \%$ level. If not otherwise stated differences are significant for all three approaches (normal, percentile, and bias corrected).

Table 17: Decomposition of log hourly wage gap, males/females, BHPS 1991-2002

\begin{tabular}{lllllll}
\hline Male/Female & & & & & \\
Year & 1991 & 1992 & 1993 & 1994 & 1995 & 1996 \\
\hline $\ln \bar{W}^{C M}-\ln \bar{W}^{C F}$ & $0.2584^{* *}$ & $0.2887^{* *}$ & $0.3363^{* *}$ & $0.2871^{* *}$ & $0.3194^{* *}$ & $0.2267^{* *}$ \\
$\% \Delta$ non-carers & -0.0564 & -0.0420 & 0.0022 & -0.0348 & 0.0211 & -0.0937 \\
$\hat{\beta}^{C M}\left(\bar{X}^{C M}-\bar{X}^{C F}\right)$ & $0.0689^{* *}$ & $0.0640^{* *}$ & $-0.2637^{* *}$ & $0.2641^{* *}$ & $0.0509^{* *}$ & $-0.2296^{* *}$ \\
$\bar{X}^{C F}\left(\hat{\beta}^{C M}-\hat{\beta}^{C F}\right)$ & $0.1895^{* *}$ & $0.2247^{* *}$ & $0.6000^{* *}$ & 0.0231 & $0.2685^{* *}$ & $0.4564^{* *}$ \\
$\hat{\beta}^{C F}\left(\bar{X}^{C M}-\bar{X}^{C F}\right)$ & $0.0607^{* *}$ & $0.0972^{* *}$ & $0.0075^{* *}$ & $0.0710^{* *}$ & $0.0611^{* *}$ & $0.0707^{* *}$ \\
$\bar{X}^{C M}\left(\hat{\beta}^{C M}-\hat{\beta}^{C F}\right)$ & $0.1977^{* *}$ & $0.1916^{* *}$ & $0.3288^{* *}$ & $0.2161^{* *}$ & $0.2583^{* *}$ & $0.1560^{* *}$ \\
\hline & 1997 & 1998 & 1999 & 2000 & 2001 & 2002 \\
\hline $\ln \bar{W}^{C M}-\ln \bar{W}^{C F}$ & $0.2599^{* *}$ & $0.1667^{* *}$ & $0.1903^{* *}$ & $0.2909^{* *}$ & $0.3020^{* *}$ & $0.3065^{* *}$ \\
$\% \Delta$ non-Carers & -0.0416 & -0.1503 & -0.1256 & -0.0063 & -0.0029 & -0.0427 \\
$\hat{\beta}^{C M}\left(\bar{X}^{C M}-\bar{X}^{C F}\right)$ & $0.2268^{* *}$ & $0.0648^{* *}$ & $0.0856^{* *}$ & $0.2256^{* *}$ & $0.1770^{* *}$ & $0.0531^{* *}$ \\
$\bar{X}^{C F}\left(\hat{\beta}^{C M}-\hat{\beta}^{C F}\right)$ & $0.0331^{* *}$ & $0.1019^{* *}$ & $0.1046^{* *}$ & $0.0654^{* *}$ & $0.1250^{* *}$ & $0.2534^{* *}$ \\
$\hat{\beta}^{C F}\left(\bar{X}^{C M}-\bar{X}^{C F}\right)$ & $0.0860^{* *}$ & $0.0696^{* *}$ & $0.0998^{* *}$ & $0.0606^{* *}$ & $0.0127^{* *}$ & $0.0919^{* *}$ \\
$\bar{X}^{C M}\left(\hat{\beta}^{C M}-\hat{\beta}^{C F}\right)$ & $0.1739^{* *}$ & $0.0971^{* *}$ & $0.0905^{* *}$ & $0.2303^{* *}$ & $0.3147^{* *}$ & $0.2146^{* *}$ \\
\hline
\end{tabular}

Note: Significance is based on $95 \%$ and $90 \%$ bootstrap confidence intervals for 500 replications, ** and $*$ indicate significance at $95 \%$ and $90 \%$ level. If not otherwise stated differences are significant for all three approaches (normal, percentile, and bias corrected). 
Table 18: Hourly wage gap for carers caring, BHPS 1991-2002

\begin{tabular}{lllll}
\hline & All & Female & Male & Male/Female \\
\hline $\ln \bar{W}^{C M}-\ln \bar{W}^{C F}$ & $0.0592^{* *}$ & $0.0213^{*}$ & $0.0639 * *$ & $0.2695^{* *}$ \\
$\hat{\beta}^{N C}\left(\bar{X}^{N C}-\bar{X}^{C}\right)$ & $0.0170^{*}$ & $0.0105^{*}$ & $0.0360^{*}$ & $-0.0222^{*}$ \\
$\bar{X}^{C}\left(\hat{\beta}^{N C}-\hat{\beta}^{C}\right)$ & $0.0422^{*}$ & 0.0107 & $0.0279^{*}$ & $0.2917^{* *}$ \\
$\hat{\beta}^{C}\left(\bar{X}^{N C}-\bar{X}^{C}\right)$ & $0.1096^{*}$ & $0.3891^{*}$ & $-0.1007^{*}$ & $0.0076^{*}$ \\
$\bar{X}^{N C}\left(\hat{\beta}^{N C}-\hat{\beta}^{C}\right)$ & -0.0504 & $-0.3678^{*}$ & $0.1646^{*}$ & $0.2619 * *$ \\
\hline
\end{tabular}

Note: Significance is based on $95 \%$ and $90 \%$ bootstrap confidence intervals for 500 replications, $* *$ and * indicate significance at $95 \%$ and $90 \%$ level. If not otherwise stated differences are significant for all three approaches (normal, percentile, and bias corrected).

Table 19: Hourly wage gap for carers caring $>20$ hours

\begin{tabular}{lllll}
\hline & All & Female & Male & Male/Female \\
\hline $\ln \bar{W}^{C M}-\ln \bar{W}^{C F}$ & $0.1160^{* *}$ & $0.0939^{* *}$ & $0.1776^{* *}$ & $0.2005^{* *}$ \\
$\hat{\beta}^{N C}\left(\bar{X}^{N C}-\bar{X}^{C}\right)$ & $0.0087^{*}$ & $0.0661^{*}$ & 0.0079 & $0.1237^{*}$ \\
$\bar{X}^{C}\left(\hat{\beta}^{N C}-\hat{\beta}^{C}\right)$ & $0.1073^{* *}$ & $0.0277^{*}$ & $0.1697^{* *}$ & $0.0768^{*}$ \\
$\hat{\beta}^{C}\left(\bar{X}^{N C}-\bar{X}^{C}\right)$ & $0.0161^{*}$ & -0.0025 & $-0.0536^{*}$ & 0.1355 \\
$\bar{X}^{N C}\left(\hat{\beta}^{N C}-\hat{\beta}^{C}\right)$ & $0.0999^{*}$ & $0.0963^{*}$ & $0.2312^{*}$ & 0.0651 \\
\hline
\end{tabular}

Note: Significance is based on $95 \%$ and $90 \%$ bootstrap confidence intervals for 500 replications, $* *$ and * indicate significance at $95 \%$ and $90 \%$ level. If not otherwise stated differences are significant for all three approaches (normal, percentile, and bias corrected).

Table 20: Hourly wage gap non-carers/carers, BHPS 1997-2002

\begin{tabular}{lllll}
\hline & All & Female & Male & Male/Female \\
\hline $\ln \bar{W}^{C M}-\ln \bar{W}^{C F}$ & $0.0963^{* *}$ & $0.0555^{* *}$ & $0.1045^{* *}$ & $0.2565^{* *}$ \\
$\hat{\beta}^{N C}\left(\bar{X}^{N C}-\bar{X}^{C}\right)$ & $0.0522^{*}$ & $0.0797^{*}$ & $0.0379^{*}$ & $-0.2521^{*}$ \\
$\bar{X}^{C}\left(\hat{\beta}^{N C}-\hat{\beta}^{C}\right)$ & $0.0441^{*}$ & $-0.0242^{*}$ & $0.0665^{*}$ & $0.5086^{* *}$ \\
$\hat{\beta}^{C}\left(\bar{X}^{N C}-\bar{X}^{C}\right)$ & $-0.0994^{*}$ & $0.1414^{*}$ & $-0.2161^{*}$ & $-0.0651^{*}$ \\
$\bar{X}^{N C}\left(\hat{\beta}^{N C}-\hat{\beta}^{C}\right)$ & $0.1957^{*}$ & $-0.0858^{*}$ & $0.3206^{*}$ & $0.3216^{* *}$ \\
\hline
\end{tabular}

Note: Significance is based on $95 \%$ and $90 \%$ bootstrap confidence intervals for 500 replications, $* *$ and * indicate significance at $95 \%$ and $90 \%$ level. If not otherwise stated differences are significant for all three approaches (normal, percentile, and bias corrected). 
Table 21: Gross and net opportunity costs of caring from forgone wages

\begin{tabular}{lll|l}
\hline & Non-participant & & Participant \\
& High & Low & \\
\hline $\begin{array}{l}\text { Definition of opportunity } \\
\text { cost }\end{array}$ & $\begin{array}{l}\text { Forgone wage } \\
\text { predicted from } \\
\text { participating } \\
\text { non-carers } \\
\text { model }\end{array}$ & $\begin{array}{l}\text { Forgone wage } \\
\text { predicted from } \\
\text { participating } \\
\text { carers model }\end{array}$ & $\begin{array}{l}\text { Opportunity cost } \\
\text { due to } \\
\text { unexplained part } \\
\text { in the wage gap } \\
\text { for carers }\end{array}$ \\
& & & \\
Gross cost $(£)$ & 32971.68 & 26030.27 & 5953.80 \\
Market value low $(£ / h r s)^{1}$ & 7.50 & 7.50 & \\
Market value high $(£ / h r s)^{1}$ & 9.24 & 9.24 & \\
Net cost low $(£)$ & 22721.92 & 21492.09 & \\
Net cost high $(£)$ & 15780.51 & 14550.68 & \\
\hline
\end{tabular}

Note: ${ }^{1}$ Taken from the Scottish Executive Central Research Unit (2001, 2002), the lower value refers to estimates for West Lothian, the higher to nation-wide estimates. If not otherwise stated costs refer to the total years spent caring between 1991 and 2002. Net costs are the difference between gross costs and the replacement costs based on the average hours cared per week. High refers to non-carer hours worked and non-carer wages, low refers to carer hours worked and carer wages. All costs are averages over relevant group of individuals. 